\title{
Advanced analysis of oligomeric proanthocyanidins: latest approaches in liquid chromatography and mass spectrometry based analysis
}

\author{
Nico Symma $\cdot$ Andreas Hensel $(\mathbb{D}$
}

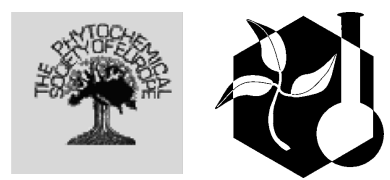

Received: 1 March 2021 / Accepted: 12 June 2021 / Published online: 24 June 2021

(C) The Author(s) 2021

\begin{abstract}
Proanthocyanidins (PAC) are an important and widely spread class of natural products with various bioactivities. The analytical evaluation of oligomeric and polymeric proanthocyanidins in complex extracts is still challenging, due to the complexity of structures. Nevertheless, in the last 20 years analytical techniques especially in the field of chromatography and mass spectrometry have been improved and offer exciting possibilities for a deeper insight into plant secondary metabolism. While classical colorimetric methods and protocols for partial hydrolysis are still valuable tools new chromatographically and mass spectrometric methods provide deep insights into the PAC fine structure, also of polymeric material. The present review focus on recent innovative LC-MS and MALDI-TOF methods, innovative strategies for advanced processing of LC-HRMS data (van Krevelen plots, Kendrick Mass Defect Analysis), MS/MS fragmentation, and newest two-dimensional LC $\times$ LC (Offline, Online, Stop-flow-2D) chromatography. Also MALDI-TOF imaging provides exciting inside in PAC distribution within biological samples and functional assays.
\end{abstract}

N. Symma · A. Hensel $(\bowtie)$

Institute of Pharmaceutical Biology and Phytochemistry, University of Münster, Corrensstraße 48, 48149 Münster, Germany

e-mail: ahensel@uni-muenster.de
Keywords Proanthocyanidins $\cdot$ Analytics $\cdot$ Mass spectrometry $\cdot$ MS imaging - Two dimensional chromatography $\cdot$ Kendrick mass defect

$\begin{array}{ll}\text { Abbreviations } \\ \text { AUC } & \text { Area under the curve } \\ \text { BFF } & \text { Benzofuran forming fission } \\ \text { DHB } & \text { 2,5-Dihydroxybenzoic acid } \\ \text { DMACA } & \text { p-Dimethylaminocinnamaldehyde } \\ \text { DP } & \text { Degree of polymerization } \\ \text { DTAF } & \text { 5-([4,6-Dichlorotriazin-2- } \\ & \text { yl]amino)fluorescein } \\ \text { EIC } & \text { Extracted ion chromatogram } \\ \text { ESI } & \text { Electrospray } \\ \text { FLD } & \text { Fluorescence detection } \\ \text { HILIC } & \text { Hydrophilic interaction liquid } \\ & \text { chromatography } \\ \text { HMB } & \text { 2-Hydroxy-5-methoxybenzoic acid } \\ \text { HRF } & \text { Heterocyclic ring fission } \\ \text { IAA } & \text { trans-3-Indoleacrylic acid } \\ \text { KMD } & \text { Kendrick Mass Defect } \\ \text { LC } & \text { Liquid chromatography } \\ \text { MALDI } & \text { Matrix assisted laser desorption ionization } \\ \text { mDP } & \text { Mean degree of polymerization } \\ \text { MS } & \text { Mass spectrometry } \\ \text { NP } & \text { Normal phase } \\ \text { PAC } & \text { Proanthocyanidins } \\ \text { PC } & \text { Procyanidin } \\ \text { PD } & \text { Prodelphinidin } \\ \text { QM } & \text { Quinone methide or interflavan fission }\end{array}$




$\begin{array}{ll}\text { RDA } & \text { Retro-Diels-Alder fission } \\ \text { RP } & \text { Reversed phase } \\ \text { TIC } & \text { Total ion chromatogram } \\ \text { TOF } & \text { Time of flight } \\ \text { UHPLC } & \begin{array}{l}\text { Ultra-high performance liquid } \\ \text { chromatography }\end{array}\end{array}$

\section{Introduction}

Proanthocyanidins (PAC, syn. condensed tannins) are polyphenolic secondary plant metabolites with tanninlike properties. PAC are widely distributed over the plant kingdom and the biosynthetic formation can be attributed to an effective defence strategy against attacks of the plants by bacteria, fungi, viruses, protozoa or helminths (Peter Constabel et al. 2014; Petridis 2011). Due to the astringent taste of PAC, PAC-containing plants protect themselves against grazing livestock (Peter Constabel et al. 2014). Further biological functions of PAC are the protection of the plants from UV irradiation due to a large chromophore and the protection from heavy-metals by chelation by the hydroxyl groups of PAC (Aerts et al. 1999; Peter Constabel et al. 2014).

As PAC are part of manifold food crops and medicinal plants, they are relevant ingredients of foods, beverages and herbal medicines. Within food technology PAC strongly contribute to many relevant properties of the processed products as e.g., colour, taste, texture, and stability. PAC in medicinal plants and in extract-containing phytopharmaceuticals are in many cases assessed as active ingredients, responsible for potential antidiarrheal and wound-healing effects, but also with clinically relevant impact for its documented cardioprotective, neuroprotective, antioxidant, antiinflammatory, antimicrobial and antiviral effects (Gescher et al. 2011; Halver et al. 2019; Löhr et al. 2011; Luca et al. 2020; Neilson et al. 2016; Rauf et al. 2019; Santos-Buelga and Scalbert 2000). As PAC therefore influence the specific properties and functionality of many plant-based products the exact analytical characterization of these polyphenols is essential. This refersnot only to the structural features of the respective PAC fractions, but also to the extractability of these polyphenols into the processed products. As PAC are known to be highly sensitive against oxidation, a need for stability monitoring of these polyphenols in products is desirable, as degradation, polymerisation and oxidation might fundamentally change relevant properties of the respective products (Jorgensen et al. 2004).

PAC are complex oligomers or polymers, consisting of flavan-3-ol building blocks, mainly (epi)afzelechin, (epi)catechin and (epi)gallocatechin, while (epi)fisetinidol and (epi)robinetinidol are rather rare PAC building blocks (Fig. 1) (Hümmer and Schreier 2008). Complexity is caused not only by the different degrees of polymerization, but also by variable hydroxylation of the B-ring, the stereochemical properties (especially at $C-2$ and $C-3$ ), the respective interflavan linkages (B-type: $4 \rightarrow 6$ or $4 \rightarrow 8$, or A-type: $4 \rightarrow 8$ and $2 \rightarrow O \rightarrow 7$ ), the specific stereochemistry at the interflavan bridging points and the potential substitution pattern (Santos-Buelga and Scalbert 2000). Additional substitution of the PAC backbone is frequently observed by galloylation at position O-3 (Nonaka et al. 1983; Prieur et al. 1994; Schmuch et al. 2015), benzoylation (Anke et al. 2008) as well as $O$ - and $C$-glycosylation (Gujer et al. 1986; Santos-Buelga and Scalbert 2000). Also substitution of the upper flavan-3-ol unit with phenylpropanoid units is observed, leading to the formation of so called cinchonains (Nonaka et al. 1982; Sendker et al. 2013) (Fig. 2). Some authors differentiate between oligomeric and polymeric PAC, due to the degree of polymerization, but as a universal and binding definition is still missing, a clear classification into oligomeric and polymeric PAC is still not feasible (Ou and Gu 2014; Salminen 2018).

Due to the high variability and complexity PAC are still assessed as a class of natural products, for which detailed structural characterization is challenging. Although protocols for analytical characterization of complex polymers are well established e.g., in the fields of hydrocarbons from petrol chemistry or plastic industry, or polysaccharides within plants, the analytical assessment of PAC, describing the huge variety of the PAC pool within one plant part or within one single product is complicated due to the high structural diversity (Neilson et al. 2016).

This review summarizes the most relevant chromatographic and mass spectrometric methods, introduces the latest innovations, and focuses especially on off- and online two-dimensional chromatography, coupled with MS detection, and pinpoints improved 


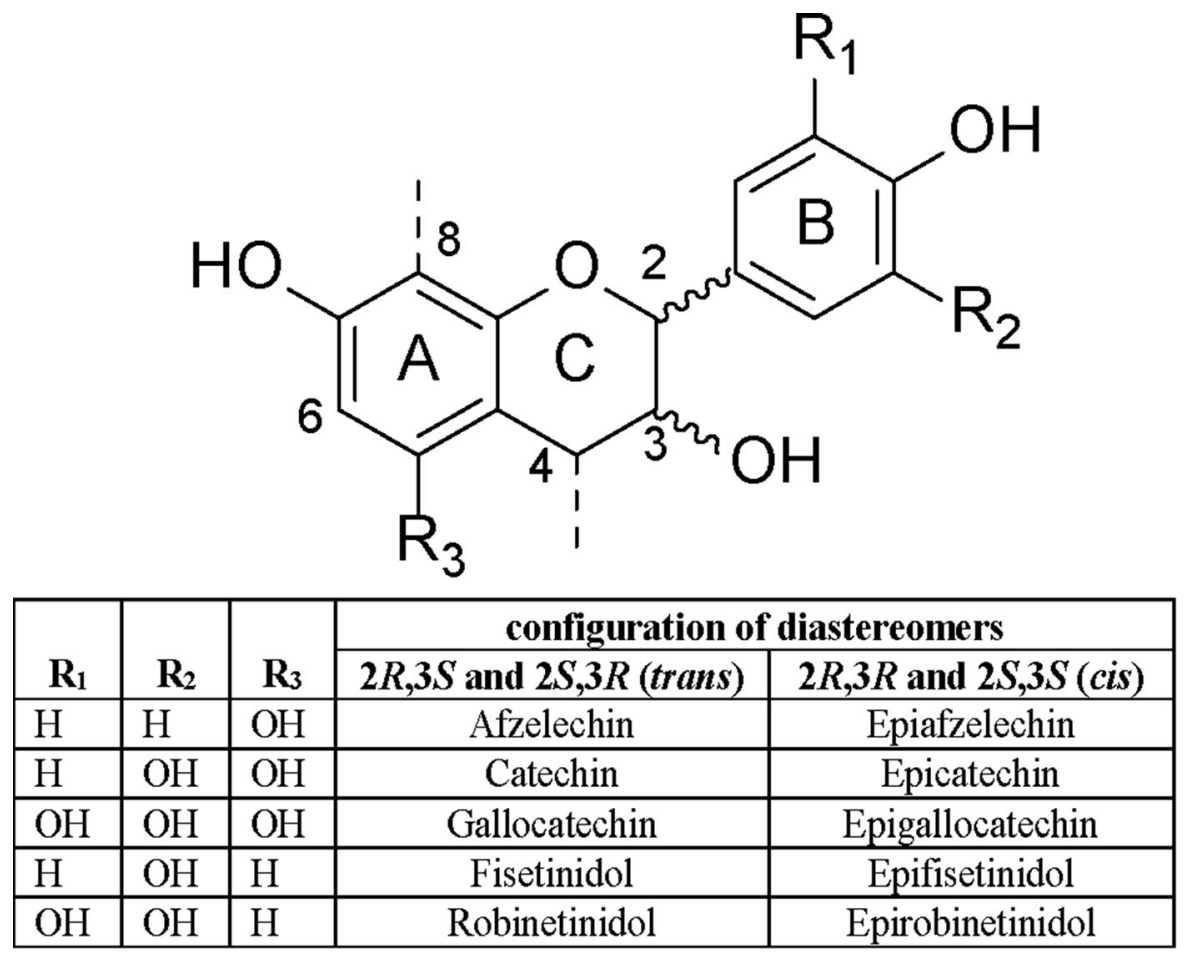

Fig. 1 Typical PAC building blocks, depending on the number and position of hydroxyl groups and stereochemistry in positions 2 and 3. a, b, c: A-, B-, and C-ring, respectively

strategies of analyzing and presenting complex data from high resolution mass spectrometry (HR-MS) of PAC containing samples. NMR analysis of PAC is not reviewed in this context, as unfortunately less innovations in this field have been reported within the last years.

\section{Established approaches for general PAC analysis}

Colorimetric methods

Basic analytical characterization of PAC started within the last century by the use of colorimetric methods. These methods are generally based on the formation of colored products, using either the redox activity of the flavan-3-ol polymers or their reactivity with aromatic aldehydes (Rohr et al. 2000). Assays using the redox activity of polyphenols are the Prussian blue assay, introduced by Price and Butler (1977) (Graham 1992; Price and Butler 1977), oxidizing the phenolic hydroxyl groups by use of $\mathrm{K}_{3} \mathrm{Fe}(\mathrm{CN})_{6}$ and $\mathrm{FeCl}_{3}$ in $\mathrm{HCl} 0.1 \mathrm{~mol} / \mathrm{L}$ leading to the formation of Prussian blue (Rohr et al. 2000). A similar principle is used by the Folin-Ciocalteu reagent, the official method for quantification of the tannin content in herbal materials in the European Pharmacopeia (European Pharmacopoiea 10.0 2020). The protocol is based on a redox reaction of polyphenols with a mixture of phosphomolybdate and phosphotungstate, which yields colored products (Schofield et al. 2001). The total tannin content can be determined by the measurement of the UVabsorption before and after addition of hide powder (a standardized protein-containing reagent, reacting with tannin-like compounds to the PAC sample) (European Pharmacopoiea 10.0 2020; Rohr et al. 2000) (Rohr et al. 2000). Both methods are not PAC specific, but can easily be used for quantification of the different classes of polyphenolic tannins (Schofield et al. 2001). Quantification and calibration of the polyphenol content is generally calculated against gallic acid or pyrogallol equivalents (Kelm et al. 2005; Rohr et al. 2000).

In contrast, assays using e.g., vanillin- or $p$ dimethylaminocinnamaldehyde (DMACA) exert 


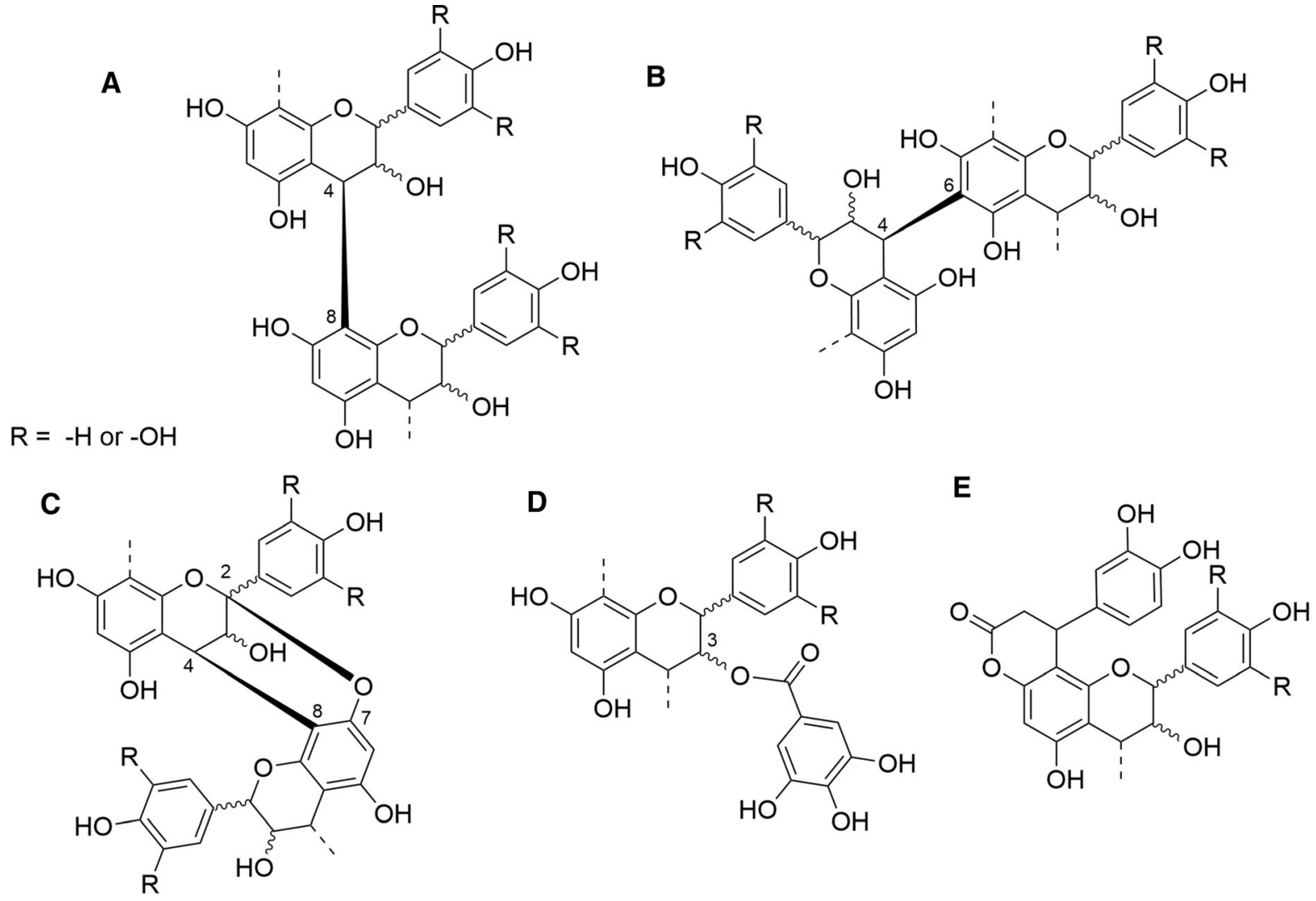

Fig. 2 Examples for PAC structural variability. a: $(4 \beta \rightarrow 8)$ B-type linkage; b: $(4 \beta \rightarrow 6)$ B-type linkage; c: $(4 \beta \rightarrow 8)$ and $(2 \beta \rightarrow O \rightarrow 7)$ A-type linkage; d: 3-O-galloylated PAC; e: cinchonain

higher specificity for PAC. These methods are based on the reaction of the aromatic aldehydes with the phloroglucinol moieties of PAC in acidic solution, leading to coloured products, which can be qualitatively and quantitatively determined by UV/Visspectroscopy. Cross reactions by other meta-substituted phenols have been described (Rohr et al. 2000; Sarkar and Howarth 1976; Schofield et al. 2001).

An alternative to these assays is the acid-butanol assay, which is based on the heterolytic cleavage of the interflavan linkage of PAC polymers, forming coloured anthocyanidins and the respective flavan-3ol (Rohr et al. 2000; Schofield et al. 2001).

Nevertheless, quantitative data, obtained by the different colorimetric methods have to be handled with care, as all results obtained strongly depend on the respective calibration standard, on the solvents used and the specific reaction protocols (Hümmer and Schreier 2008; Kelm et al. 2005; Neilson et al. 2016; Rohr et al. 2000). Additionally, interactions with other
non-PAC matrix components have to be considered and also differences in the reactivity between different monomer types or between monomers and polymers have been described (Hümmer and Schreier 2008; Kelm et al. 2005; Neilson et al. 2016; Rohr et al. 2000).

Colorimetric methods can be performed quickly and with limited technical requirements. They provide qualitative information regarding the presence of PAC in general, but they cannot distinguish between structural modifications of the polymers as, e.g. the different building blocks or the degree of polymerisation. Therefore, colorimetric methods are not suited for structural analysis of PAC. PAC quantitation by colorimetric methods is possible, but this requires external calibration standards, which in many cases are not really related to the PAC structures of the investigated product. 
Degradation methods

Thiolysis and phloroglucinolysis of PAC are based on the reaction of the PAC interflavan linkage with nucleophiles, either with thiols e.g., benzyl mercaptan (Guyot et al. 2001; Rigaud et al. 1991), 2-mercaptoethanol (Tanaka et al. 1994) or cysteamine (Gao et al. 2018; Torres and Lozano 2001). The respective reactions will typically lead to the formation of thioethers. Also phloroglucinol can be used for PAC derivatisation (Kennedy and Jones 2001; KoupaiAbyazani et al. 1992). The nucleophiles react in acidic solution with the upper part (extension units) of the polymer chain to nucleophile-monomer adducts, whereas the terminal building block is released as the respective flavan-3-ol (Hümmer and Schreier 2008; Schofield et al. 2001). Subsequent HPLC-UV or MS analysis of the released fragments (flavan-3-ols and the respective phloroglucinol adducts or thioethers) identifies the respective building blocks. Also comparison of the AUCs of the extender-adducts and the terminal flavan-3-ol can be used for the calculation of a mean degree of polymerization (mDP), and the ratios of (epi)afzelechin/(epi)catechin/(epi)gallocatechin (Hümmer and Schreier 2008; Neilson et al. 2016). As typically the A-type interflavan linkage and gallic esters are not cleaved by this type of reaction, also the percentage of A-type linkages and the percentage of galloylation can be calculated (Gao et al. 2018; Kimura et al. 2011; Neilson et al. 2016; Torres and Lozano 2001). Compared to thiolysis, phloroglucinol is mostly preferred for the degradation of PAC, as the reagent is easier to handle, due to the unpleasant odour of the used toxic mercaptans (Kennedy and Jones 2001; Schofield et al. 2001). Both degradation methods are suited for characterization of the polymer by calculated mean values and for the unambiguous identification of the building blocks (Kawakami et al. 2018; Kelm et al. 2005; Neilson et al. 2016).

These methods are suitable for getting a first insight into the PAC content of a sample and can be used for a rough qualitative screening, but these protocols do not give a comprehensive overview on the respective PAC composition and give no insight in fine structures. As the structure of PAC within a given sample affects its functionality and bioactivity, identification of intact PAC chains is desirable (Xie and Dixon 2005). Since 2000 advanced chromatographic and MS techniques have been developed, offering a deeper view into PAC structure, especially with respect to potential oligomers with higher DP and potential secondary modifications.

Liquid chromatography-mass spectrometry (LCMS)

Whereas the eighties' and nineties' of the last century was the time of the colorimetric methods, combined with simple identification methods of building blocks, the new millennium opened doors for improved chromatographic separation of complex PAC mixtures, followed later on also by hyphenated techniques. The reviews of Hümmer et al. (2008), de Villiers et al. (2016) and Rue et al. (2018) display a variety of established LC and LC-MS approaches and protocols for PAC analysis.

In principle, the chromatography preferred today is the ultra-high performance liquid chromatography (UHPLC), as it combines fast separation of analytes with high resolution (Motilva et al. 2013; Villiers et al. 2016). Besides normal phase (NP) (Lazarus et al. 1999; Rigaud et al. 1993) and reversed phase chromatography (RP) (Hümmer and Schreier 2008), hydrophilic interaction liquid chromatography (HILIC) (Kelm et al. 2006; Yanagida et al. 2007) has been extensively used in nowadays PAC analysis. Typically, detection is performed by UV/Vis, fluorescence, or ESI-MS (Hümmer and Schreier 2008). In contrast to NP chromatography, RP and also HILIC stationary phases can be combined with ESI-MS detection, as this ionization requires hydrophilic and volatile solvents. RP chromatography is typically performed on a RP18 stationary phase in combination with binary gradients, mostly based on a water/ acetonitrile mixtures (Hümmer and Schreier 2008). In RP chromatography, PAC only get sufficiently separated up to DP 4, and it has to be kept in mind that the respective elution order of the peak clusters is not necessarily correlated to the respective DP. Especially secondary modification of PAC, as e.g. galloylation has strong impact on the retention behavior (Symma et al. 2020). In many cases an increased baseline, often called "bump" (Kalili and Villiers 2009), is observed, which indicates that most of the oligomers and polymers remain unresolved in RP chromatography (Frost et al. 2018; Guyot et al. 1997; Rohr et al. 2000). NP chromatography is based on hydrophilic stationary 
phases and a mobile phase gradient starting usually with more lipophilic solvent towards increasing hydrophilicity e.g., from methylene chloride to methanol. NP chromatography separates PAC according to the molecular weight. PAC oligomers with low DP elute earlier than higher DP PAC (Hammerstone et al. 1999; Lazarus et al. 1999). Typically, the chromatograms are characterized by distinct peak series, each representing an oligomer cluster with defined DP (Hammerstone et al. 1999; Lazarus et al. 1999). It has to be kept in mind that this kind of chromatography is not appropriate to be connected to an ESI-MS detector, due to the low hydrophilicity of the solvents. A milestone in PAC analysis in 2006 was the introduction of HPLC on diol stationary phase, in combination with a binary gradient ranging from acetonitrile to a more hydrophilic system as e.g. methanol/water mixtures (Kelm et al. 2006). This principle led to optimized separation of PAC clusters of more than DP10 (Kelm et al. 2006; Robbins et al. 2012). Diol phase chromatography can be assessed to be a kind of hydrophilic-lipophilic interaction chromatography (HILIC), which again is a variation of NP chromatography, where separation is performed on a hydrophilic stationary phase with partly aqueous eluents (Hemström and Irgum 2006). PAC analysis of diol phases provides a good overview on the respective DP distribution of complex samples and can easily be used for quantification of individual clusters and also for determination of the total PAC content (Hellenbrand et al. 2015a, 2015b). While oligomers elute with lower retention as distinct peaks, PAC polymers are typically found as a broad, chromatographically unresolved hump, which can also get quantified (Hellenbrand et al. 2015a, b). Acidification of the mobile phase (formic acid, acetic acid, trifluoric acid) in low concentrations reduces peak broadening and should be used routinely for PAC analysis (Hümmer and Schreier 2008; Motilva et al. 2013; Russo et al. 2020). The peak clusters are characterized only by the same DP, but can consist of oligomers with different fine structures (e.g., different hydroxylation pattern of the building blocks, different linkages types etc.). Secondary modification of the DP clusters will change the retention behavior, which means that unmodified PAC clusters elute in a clear and unambiguous sequence, while for modified PAC with e.g., galloylation or multiple hydroxylation a clear cluster formation cannot be observed (Montero et al. 2013a; Symma et al. 2020). Consequently, diol chromatography of PAC mixtures is very efficient for unmodified PAC strains, but mixtures of unmodified and modified PAC can result in chromatograms which are hard to interpret. Therefore, a disadvantage of HILIC chromatography is the limited structural information on the respective DP clusters (Kelm et al. 2006). Up to now chromatographical resolution is possible for unmodified PAC extracts up to around DP 15 , followed by an unresolved hump of polymeric PAC (Hellenbrand et al. 2015a, b).

PAC detection after chromatographic separation is mostly performed by UV at $\lambda_{\max } 280 \mathrm{~nm}$. Fluorescence detection (FLD) at $\lambda_{\mathrm{ex}} 280 \mathrm{~nm}$ and $\lambda_{\mathrm{em}} 316 \mathrm{~nm}$. FLD provides very sensitive and specific detection of PAC and should be preferred for complex PACcontaining matrices rather than UV detection. It has to be kept in mind that for galloylated PAC quenching of the respective fluorescent signals was observed, leading to significant underestimation of the peak size of such compounds. In such cases UV detection will lead to more valid results (Hammerstone et al. 2000).

MS detection-in most cases ESI-MS-is used to obtain detailed insight into the fine structure of peaks clusters (Hümmer and Schreier 2008). Especially high resolution mass spectrometry (HR-MS) provides accurate $\mathrm{m} / \mathrm{z}$ values and enables the calculation of molecular formulae, which is important for the exact classification and differentiation of the molecular ions (Sendker et al. 2013; Symma et al. 2020). LC-MS analysis can also provide validation of the elution profiles obtained after HILIC separation. DP and the respective retention times reveal typically a logarithmic correlation. ESI-MS is often combined together with a time of flight (TOF) analyzer, as TOF has principally no mass limit. Realistically, PAC only up to DP 20 can be detected. This is due to the increasing complexity of PAC chains with increasing DP and the decreasing ionization of long chain PAC, as has been reported for PAC analysis by MALDI-TOF (Hümmer and Schreier 2008).

ESI-MS analysis of PAC can be performed in both, positive and negative ion mode. In contrast to MALDI-MS, ESI-MS in the positive mode produces not only single charged ions $\left([\mathrm{M}+\mathrm{H}]^{+},[\mathrm{M}+\mathrm{Na}]^{+}\right.$, $[\mathrm{M}+\mathrm{K}]^{+},\left[\mathrm{M}+\mathrm{NH}_{4}\right]^{+}$), but also multiple charged ions $[\mathrm{M}+\mathrm{nX}]^{\mathrm{n}+}$ and Coulomb multimers $[\mathrm{nM}+\mathrm{X}]^{+}$. Therefore, detailed interpretation of ESI mass spectra in the positive ionization is more 
complex (Symma et al. 2020) compared to the data obtained in the negative mode (Motilva et al. 2013). Additionally, in-source fragmentation can occur within both ionization modes and has to be considered by the interpretation of mass spectra (Kuhnert et al. 2013). ESI-MS is mostly performed in devices, which enable additional MS/MS fragmentation. PAC undergo specific fragmentation reactions, i.e. RetroDiels-Alder fission (RDA; neutral loss of $152 u$ ), quinone methide or interflavan fission (QM; neutral loss of $288 u$ (upper units) or $290 u$ (terminal unit)), heterocyclic ring fission (HRF; neutral loss of $126 u$ ) and benzofuran forming fission (BFF, neutral loss of 122 u) (Fig. 3) (Gu et al. 2003; Li and Deinzer 2007). Using these fragmentation sequences, identification and sequencing of individual PAC polymer ions is possible (Gu et al. 2003; Li and Deinzer 2007).

LC-MS methods, especially those based on HILIC mode separation on diol stationary phase, are still very promising in PAC analysis, as they provide specific information on the distribution of DP clusters of the PAC containing samples. Additional information of PAC fine structure can be gained by MS/MS sequencing of single PAC ions. Nevertheless, the detailed composition of individual DP clusters cannot be elucidated e.g., with respect to slight modifications, as e.g. A-types or differentially hydroxylated building blocks. Furthermore, PAC clusters can only be separated up to maximum of DP 15 by the respective chromatographic methods Therefore, LC-MS in HILIC mode cannot provide information regarding the presence and the composition of higher DP polymers.

\section{MALDI-TOF mass spectrometry}

MALDI-TOF, well suited for the analysis of high molecular weight compounds (Es-Safi 2012), is an established methodology for the analysis of oligomeric PAC (Ohnishi-Kameyama et al. 1997; Yang and Chien 2000). The method has been extensively used to investigate the PAC composition of complex plant extracts (Monagas et al. 2010; Reed et al. 2005). The principles, technical possibilities, and the established protocols for MALDI-TOF PAC analysis were reviewed by Reed et al. (2005), Hümmer and Schreier (2008), Monagas et al. (2010), Domínguez-Rodríguez et al. (2017), Es-Safi (2012) and Rue et al. (2018).
In brief, MALDI-TOF analysis of PAC can be performed in both, linear or reflectron mode. Mass spectra in the reflectron mode exhibit typically a better resolution compared to those recorded in the linear mode, leading to a better detection of secondary modifications and differences in hydroxylation pattern. In contrast, mass spectra in the linear mode are more suitable for detection of PAC polymers with a higher DP (Deng et al. 2016; Yang and Chien 2000).

In most cases measurements are performed in the positive ion mode. As plant extracts often contain cations, typically the $[\mathrm{M}+\mathrm{Na}]^{+}$and $[\mathrm{M}+\mathrm{K}]^{+}$are observed as positive molecular ions rather than $[\mathrm{M}+\mathrm{H}]^{+}$adducts, which actually are observed only in rare cases (Yang and Chien 2000). The addition of salts of metal ions e.g. $\mathrm{Li}^{+}$(Stringano et al. 2011), $\mathrm{Na}^{+}$ (Stringano et al. 2011), $\mathrm{K}^{+}$(Bianchi et al. 2015), $\mathrm{Cs}^{+}$ (Chai et al. 2014; Neto et al. 2017; van Huynh and Bevington 2014; Zhang and Lin 2008) and $\mathrm{Ag}^{2+}$ (Ohnishi-Kameyama et al. 1997) is described in literature in order to increase the signal intensity, especially for PAC with higher DP. This also reduces misinterpretations, as the naturally occurring $[\mathrm{M}+\mathrm{Na}]^{+}$and the $[\mathrm{M}+\mathrm{K}]^{+}$ions typically have a mass difference of $16 u$, pretending to be an additional hydroxyl group (Pérez-Jiménez and Torres 2012). It is also observed, that the cationizing agents can also influence the quality of the mass spectra (PérezJiménez and Torres 2012). MALDI-TOF studies of PAC in the negative ion mode are rare (Mateos-Martín et al. 2012; Rush et al. 2018).

Solutions of 2,5-dihydroxybenzoic acid (DHB) (Kawakami et al. 2018), 2-hydroxy-5-methoxybenzoic acid (HMB) and trans-3-indoleacrylic acid (IAA) have been described to generate an optimized matrix (Behrens et al. 2003; Stringano et al. 2011; Taylor et al. 2003) and provide the best results with respect to PAC detection. However, recent studies reported good results without using any matrix, with only methanol as a solvent (Pinaffi et al. 2020).

MALDI-TOF MS can detect PAC polymers with DP $>20$ (Chai et al. 2014). It is important to note, that the quality of MALDI-TOF mass spectra regarding the detectability of higher DP PAC can be significantly increased by effective sample clean-up (Neilson et al. 2016). Prefractionation of the samples by solid phase extraction or gel permeation chromatography (Sephadex LH-20, Toyopearl HW-40) helps to increase the specific and sensitive detection of PAC with higher DP 


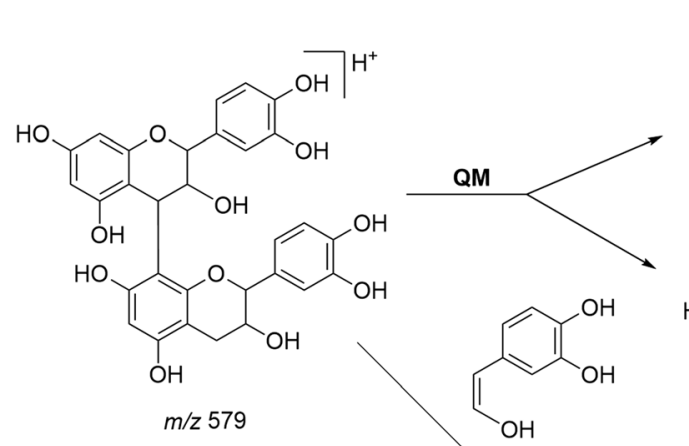<smiles>O=C1C=C(O)C2=CC(O)C(c3ccc(O)c(O)c3)OC2=C1</smiles><smiles>Oc1cc(O)c2c(c1)OC(c1ccc(O)c(O)c1)C(O)C2</smiles>

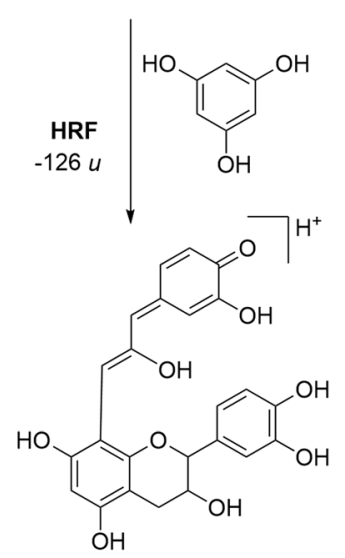

RDA $\mathrm{OH}$

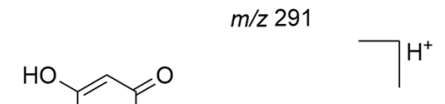

$-136 u$

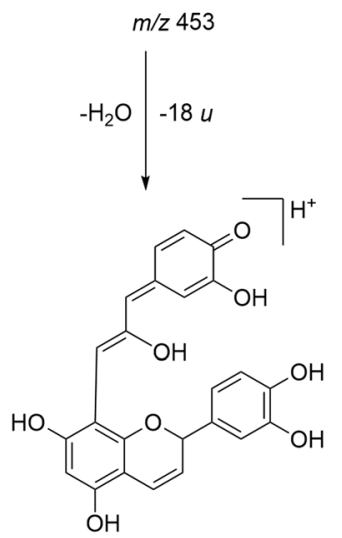

$\mathrm{m} / \mathrm{z} 435$

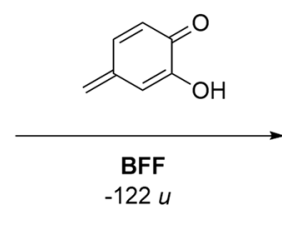

$22 u$

HO $>0$<smiles>O=C(OC1Cc2c(O)cc(O)cc2OC1c1ccc(O)c(O)c1)c1cc(O)c(O)c(O)c1</smiles>

$\mathrm{m} / \mathrm{z} 443$

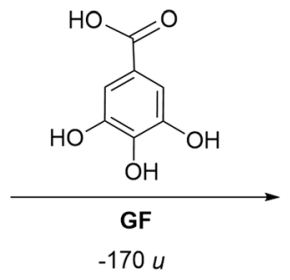<smiles>CC[C+](C)C</smiles>

$m / z 273$

Fig. 3 Theoretical mass spectrometric fragmentation scheme of a (epi)catechin B-type dimer. QM: quinone methide fission; RDA: Retro-Diels-Alder fission; HRF: heterocyclic ring fission; BFF: benzofuran forming fission; GF: gallic ester fission 
(Chai et al. 2014; Neilson et al. 2016). Cation exchange chromatography or dialysis are recommended to remove cations $\left(\mathrm{Na}^{+}\right.$or $\left.\mathrm{K}^{+}\right)$in the sample, which typically can interact and also lead to misinterpretation (Zhang and Lin 2008). In a PAC polymer fraction from brown soybean seed coat PAC homopolymers with DP up to 30 have been detected by MALDI TOF (Takahata et al. 2001). As molecular ions in MALDI-TOF analysis are predominately single charged, identification of ions is much easier, compared to data sets obtained from ESI-MS experiments (Oliveira et al. 2015; Rush et al. 2018).

Interestingly, results obtained from the same samples by use of MALDI-TOF and ESI-MS can vary, especially concerning the identification of potential PAC sub-series (Pérez-Jiménez and Torres 2012).

MALDI-TOF MS is an essential part of PAC analysis, as it provides a helpful overview on the PAC composition of plant extracts. Nevertheless, structural information is rather limited, as no MS/MS sequencing is performed and misinterpretation of signals may occur due to different cation adducts. Additionally, a typical dilemma regarding PAC identification has to be considered: Whereas the reflector mode provides good resolution for PAC ion identification, the detectability of PAC with higher DP can only be obtained using the linear mode with low resolution. In general, detectability of PAC polymers is decreasing with increasing DP with a maximum at around DP 30. Moreover, sample preparation is necessary and a MALDI-TOF mass spectrometer is not part of every standard lab.

\section{Innovative strategies}

Liquid-chromatography coupled with mass spectrometry: LC-MS

\section{One-dimensional chromatography with advanced data analysis}

PAC analysis is a challenging field in the analysis of complex plant extracts, medicinal plants, crops and food products, not only due to the structural complexity of PAC, but also because of a huge variety of further natural products, which are part of the sample matrices, and which can affect the analytical readout, e.g. mass spectra. Therefore, Kuhnert et al. (2013) called for the introduction of methods, which can differentiate between the different compound classes in a complex test sample by using further molecular characteristics apart from the routinely used ones: absorption (UV), fluorescence, hydrophilicity (LC) or molecular mass (MS) and nevertheless keep using a simple and fast setup, without time consuming isolation of single compounds (Kuhnert et al. 2013). To get rid of this problem, advanced investigation of the recorded data set can be performed: The complex data generated by LC-MS analysis contain far more information than only the accurate masses, isotopic and fragmentation patterns and may open an additional possibility to deduce more structural characteristics of the analytes. As the MS raw data might be more complex, these data sets have to be plotted to gain a deeper insight into complex sample composition (Kuhnert et al. 2013). A common mass spectrum plots the $\mathrm{m} / \mathrm{z}$ value against the respective intensity and gives quantitative information. However, this information should be handled with care, as the different ionization of different analytes has a relevant impact on the respective ion intensity (Kuhnert et al. 2013). Furthermore, from the accurate masses and the isotopic patterns potential molecular formulae can be calculated. Coupling MS with LC also reveals information on the hydrophilicity of the molecules, presented by either the total ion chromatograms (TIC) or extracted ion chromatograms (EIC) of distinct $m / z$ values (Kuhnert et al. 2013). Introducing the "Plot-whatever-you-like-strategy" Kuhnert et al. (2013) suggests, that HRMS data should be processed in different ways, leading to different kinds of plots, enabling different views on complex sample constitution. Various processing steps have been described for this, and interestingly, this kind of data management has been deduced from LC-MS analysis of products from the petrol chemistry. Especially the van Krevelen plot and the Kendrick Mass Defect (KMD) analysis provide helpful tools for the petrol industry, but also for PAC analysis (Kuhnert et al. 2013).

Van Krevelen plot The van Krevelen plot is based on the molecular formulae calculated from the accurate masses and plots the $\mathrm{H} / \mathrm{C}$ ratio against the $\mathrm{O} / \mathrm{C}$ ratio of each ion. As every compound class features a discrete ratio of protons, carbons, oxygens and other atoms, different compound classes are displayed as different regions of spot clouds within the van Krevelen plot. Therefore, a classification of ions from MS data sets to 
various compound classes like PAC is possible (Kuhnert et al. 2013). An example of polyphenol analysis using a van Krevelen plot has been reported for artificial catechin polymers, which were obtained after polymerization with acetaldehyde (VallverdúQueralt et al. 2017a). The resulting van Krevelen plot is constructed by using a three-dimensional system where the molecular mass is represented by the z-axis, and the $\mathrm{H} / \mathrm{C}$ and $\mathrm{O} / \mathrm{C}$ ratio is displayed on the $\mathrm{x}-$ and $y$-axis. In this investigation the van Krevelen plot was able to visualize the process of polymerization by comparing MS data sets from the starting mixture with the MS data after 2 and 4 h reaction times (VallverdúQueralt et al. 2017a).

Kendrick mass defect analysis In contrast, the KMD analysis has more often applied to PAC analysis in the past (Frost et al. 2018; Symma et al. 2020; VallverdúQueralt et al. 2017a, 2017b). Originally, the KMD has been introduced by Edward Kendrick in 1963 to enhance the interpretation of HR-MS data of crude petrol oil samples. To reduce table space for storing and comparing of HR-MS data, he developed a mass scale, based on $\mathrm{CH}_{2}=14.0000$ u (Kendrick 1963). Whereas the mass defect-i.e., the difference between the exact and the nominal mass-is unequal within a homologue series of a polymer, the Kendrick mass defect-i.e., the difference between the exact and nominal Kendrick mass-remains constant. It is necessary to note, that this definition is rather general, but sufficient for PAC analysis, while a more differentiated definition can be found in Fouquet et al. (2019) (Fouquet 2019). By attributing ions of every polymer class to a specific KMD, molecular ions can be compared and classified. In the next step, the KMD of an ion is correlated to the respective molecular mass and plotted in a two-dimensional plot with the mass $(\mathrm{m} / \mathrm{z}$, (Fouquet 2019), Kendrick mass (Sleno 2012) or molecular mass (Symma et al. 2020) on the $\mathrm{x}$-axis and the KMD on the y-axis (Hughey et al. 2001; Kendrick 1963). Polymers with a homogeneous elongation unit, but with a different DP line up horizontally on the same KMD level in the KMD plot. Polymers with different substitution line up horizontally as well, but at a different KMD level and polymers with other extension units, than the reference unit used for calculation of KMD values, build oblique lines in the KMD plot (Fouquet 2019). Additionally, there is also the possibility to display the intensity of individual ions as spot size to add a third dimension of information (Symma et al. 2020). Nowadays, KMD analysis is used in a wide range of scientific fields e.g., the analysis of petrochemicals (Hughey et al. 2001; Sleno 2012), synthetic polymers (Fouquet 2019; Sato et al. 2014) or biological polymers like thearubigins (Kuhnert 2010) or lignin (Dier et al. 2016; Qi et al. 2016). In general, every meaningful part of the molecule can act as a reference unit, but it is reasonable to choose an individual unit, depending on the expected polymer of the sample. For example, in case of hydrocarbons the KMD analysis is referred to the $\mathrm{CH}_{2}$ radical unit. For PAC analysis preferentially the most abundant flavan-3-ol elongation unit, which is in most cases the (epi)catechin radical should serve as a reference unit. In Fig. 4, a calculated KMD plot of hypothetical galloylated (epi)catechin B-type PAC polymers (Fig. 4a) and an experimental KMD plot from acetone/water extract of Rumex acetosa L. (Fig. 4b) are displayed in comparison. The KMD calculation is based on an (epi)catechin radical reference unit (Symma et al. 2020).

Vellverdu-Queralt et al. (2017) applied this approach in two different experimental setups. Initially-also in combination with the respective van Krevelen plots-the KMD analysis was performed with data sets from RP-UHPLC-ESI-LTQ-OrbitrapMS of artificial epicatechin polymers, generated by polymerization using acetaldehyde. The Kendrick calculation was based on an epicatechin-ethyl unit, the expected elongation unit was set with the nominal mass of $316 u$. In the Kendrick plot multiple horizontal lines of polymers up to DP 11 (as single to triple charged ions) were observed, indicating not only a simple polymerization of epicatechin monomers, but also various side reactions (Vallverdú-Queralt et al. 2017a).

Subsequently, this kind of data evaluation was applied to the MS analysis of even more complex artificial polymerization products of epicatechin and malvidin-3-O-glucoside, connected via acetaldehyde. This study revealed that the polymerization products obtained by this synthesis are highly complex and resulted in lots of side reactions as e.g., epicatechinpyrano-malvidin-3-O-glucoside and xanthylium polymers (Table 1). This study clearly confirmed, that KMD analysis is an appropriate method for 

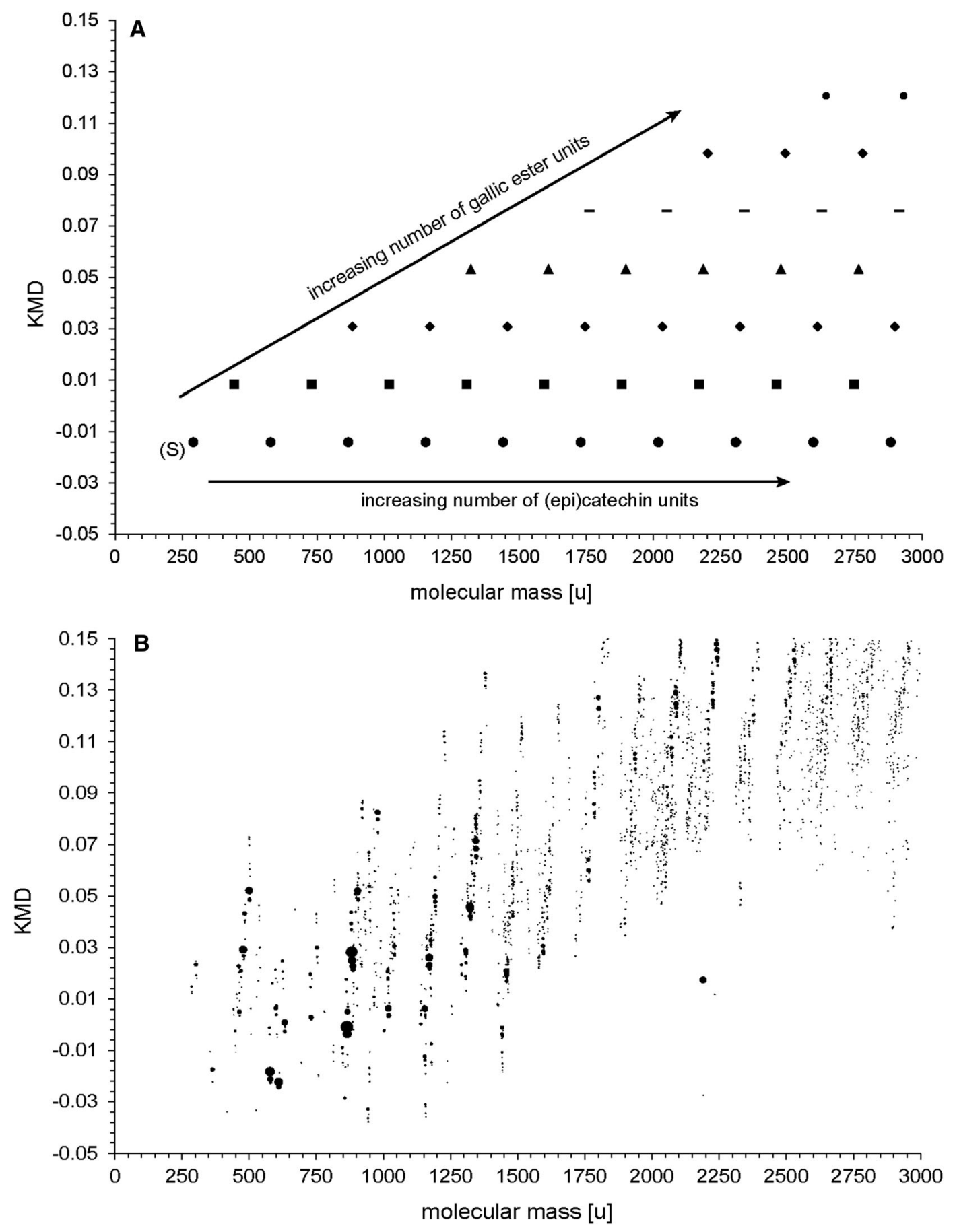

Fig. 4 KMD plots of a: calculated galloylated (epi)catechin B-type PAC polymers and $\mathbf{b}$ acetone/water extract from Rumex acetosa L.. (S): starting point: (epi)catechin

monitoring complex polymer samples (VallverdúQueralt et al. 2017b).

Frost et al. (2018) used this method in the field of red wine PAC analysis for improved detection of galloylated PAC polymers. After creating a database of molecular formulae, and theoretical exact masses of polymerization products from (epi)catechin, (epi)gallocatechin and their respective 3-O-gallates, 
differently processed red wine samples, purified by an Amberlite stationary phase, were analysed by UHPLC-ESI-Q-TOF MS on a HILIC stationary phase. The MS data were compared to the database by a KMD analysis for both, the database and the data to visualize matched compounds and polymer classes in the red wine samples. Additionally, MS/MS analysis was used to identify the compounds in detail. The respective KMD plot was based on the (epi)catechin radical with $288 u$ and revealed the presence of (epi)catechin polymers and di galloylated (epi)catechin polymers up to DP 6 (Frost et al. 2018).

Symma et al. (2020) used the KMD analysis as part of a multistep approach for PAC analysis in different medicinal plants (Hawthorn leaf and flower, Lime flower, Wisteria fruits without seeds and Common sorrel herb). Following UHPLC-FD analysis on diol stationary phase, ESI-Q-TOF analysis provides twodimensional contour plots and KMD plots. Using these data detailed PAC characteristics of each DP cluster got obvious and PAC chain fine structure were additionally identified by MS/MS fragmentation pattern (Symma et al. 2020). This work confirmed also that PAC elution in HILIC mode depends on the molecular weight or the hydrophilicity, respectively (Hümmer and Schreier 2008; Tuominen and Karonen 2018). Although the Kendrick plots of those non purified plant extracts are extremely complex, but the essential characteristics of the different PAC were easily analysed. PAC subseries e.g., A-type and B-type PAC, cinchonains and multiply hydroxylated PAC could be successfully detected. Interestingly, also series of highly galloylated PAC, which had been hard to be analysed by MALDI, could be identified in detail (Symma et al. 2020). MS/MS degradation for calculation of mean values.

A further interesting LC-MS protocol has been reported for the detailed analysis of (epi)catechin and (epi)gallocatechin PAC polymers by Engström et al. (2014). A phenyl stationary phase chromatography was coupled to a triple-quadrupole MS in the negative ion mode and PAC measurements were performed in a multiple reaction monitoring (MRM) setup, while the use of varying cone voltages produced in source fragments of PAC ions. The produced depolymerisation products were further fragmented in the collision cell, which—on the basis of heterolytic fragmentation according to the extension and terminal units-leads to different monomer ions. The ratio of the produced monomer ions leads to the calculation of the procyanidin (PC) and prodelphinidin (PD) ratios, estimation of the mean DP and estimation of the PC/PD distribution along the chromatographic run (Engström et al. 2014).

Advanced analysis of the data obtained by LC-MS is a fast and simple method to visualize complex data in an easily understandable way. Elemental and structural information can be deduced well, especially from PAC-specific KMD plots. These plots can be created directly from the MS raw data and will highlight PAC of different DP together with possible structural modifications. In contrast, Van Krevelen plot is also an interesting way of visualization of PAC MS data, but it is rather an experimental technique, as it is not PAC-specific.

\section{Two-dimensional LC $\times$ LC approaches}

A further highly relevant approach within advanced PAC analysis has been the development of two dimensional LC (2D-LC or LC $\times$ LC) protocols. The underlying principle-first mentioned by (Erni and Frei 1978) - is based on the separation of the test sample between two different (orthogonal) chromatographic systems, for which the first chromatographic dimension leads to the fractionation into distinct fractions, which are subsequently subjected to the second chromatographic system. Typically, 2D methods are labelled "comprehensive", which means, that the complete first dimension separation and the fractions gained hereby will be subjected to the second dimension. In contrast, heart cutting 2D experiments examine only the most promising fractions from the first chromatographic dimension (Cacciola et al. 2007). Both modes can either be realized as an offline, on-line, or stop-flow system (Kalili and Villiers 2013a; Montero et al. 2013a). Two-dimensional chromatography has been successfully applied to the analysis of low molecular polyphenols (Cacciola et al. 2007) and has been introduced into PAC analysis in 2009 as an offline protocol (Kalili and Villiers 2009).

Offline 2D chromatography PAC from hydroacetonic extracts from apple and cocoa fruits were analysed by HILIC diol chromatography in the first dimension for isolation of specific DP clusters, followed by RP chromatography in the second dimension, which identified potential isomers and 
Table 1 Recent methodological investigations regarding LC-MS and MALDI-TOF for the analysis of PAC in plant material and respective identified PAC series

\begin{tabular}{|c|c|c|c|}
\hline Methodology & Plant material & PAC found in the plant & References \\
\hline $\begin{array}{l}\text { Van Krevelen analysis and KMD } \\
\text { analysis }\end{array}$ & Artificial polymers & $\begin{array}{l}\text { ethyl-(epi)catechin polymers and various } \\
\text { reaction products }\end{array}$ & $\begin{array}{l}\text { Vallverdú-Queralt } \\
\text { et al. } \\
\text { (2017a, 2017b) }\end{array}$ \\
\hline KMD analysis & Vitis vinifera & $\begin{array}{l}\text { (epi)catechin, (epi)gallocatechin containing } \\
\text { B-type PAC polymers, galloylated derivatives }\end{array}$ & Frost et al. (2018) \\
\hline \multirow{4}{*}{$\begin{array}{l}\text { Multi step analysis: } \\
\text { HPLC-FD } \\
\text { Diol-LC-MS/MS } \\
\text { Contour plot } \\
\text { KMD plot } \\
\text { fragment analysis }\end{array}$} & Rumex acetosa & $\begin{array}{l}\text { galloylated (epi)catechin and (epi)afzelechin } \\
\text { containing A- and B-type PAC polymers }\end{array}$ & \multirow[t]{4}{*}{$\begin{array}{l}\text { Symma et al. } \\
(2020)\end{array}$} \\
\hline & Tilia spec & $\begin{array}{l}\text { (epi)catechin and (epi)afzelechin containing } \\
\text { A-and B-type PAC polymers }\end{array}$ & \\
\hline & Crataegus spec & $\begin{array}{l}\text { (epi)catechin and (epi)afzelechin containing A- } \\
\text { and B-type PAC polymers, cinchonains }\end{array}$ & \\
\hline & Wisteria floribunda & $\begin{array}{l}\text { (epi)afzelechin, (epi)catechin and } \\
\text { (epi)gallocatechin containing A- and B-type } \\
\text { PAC polymers }\end{array}$ & \\
\hline \multirow{2}{*}{$\begin{array}{l}\text { MS/MS degradation for calculation } \\
\text { of mean values: } \\
\text { total PAC content, total } \\
\text { procyanidins and prodelphinidins } \\
\text { including the PC/ }\end{array}$} & $\begin{array}{l}\text { Onobrychis viciifolia } \\
\text { Lotus corniculatus }\end{array}$ & $\begin{array}{l}\text { (epi)catechin and (epi)gallocatechin containing } \\
\text { PAC polymers }\end{array}$ & \multirow[t]{3}{*}{$\begin{array}{l}\text { Engström et al. } \\
\text { (2014) }\end{array}$} \\
\hline & $\begin{array}{l}\text { Securigera varia } \\
\text { Salix caprea }\end{array}$ & & \\
\hline $\begin{array}{l}\text { PD ratio, mean degree of } \\
\text { polymerization }\end{array}$ & $\begin{array}{l}\text { Coryllus avellana } \\
\text { Pinus sylvestris } \\
\text { Salix babylonica } \\
\text { Ribes rubrum } \\
\text { Ribes nigrum } \\
\text { Trifolium repens }\end{array}$ & & \\
\hline \multirow[t]{2}{*}{ Offline 2D chromatography } & Malus spec & $\begin{array}{l}\text { Malus spec.: (epi)catechin containing B-type } \\
\text { PAC polymers }\end{array}$ & $\begin{array}{l}\text { Kalili and Villiers } \\
\text { (2009) }\end{array}$ \\
\hline & Theobroma cacao & $\begin{array}{l}\text { (epi)catechin containing A- and B-type PAC } \\
\text { polymers, glycosylated PAC polymers }\end{array}$ & \\
\hline Offline $2 \mathrm{D}$ chromatography & Geranium sylvaticum & $\begin{array}{l}\text { (epi)catechin and (epi)gallocatechin containing } \\
\text { PAC polymers }\end{array}$ & $\begin{array}{l}\text { Tuominen and } \\
\text { Karonen (2018) }\end{array}$ \\
\hline Online 2D chromatography & Vitis vinifera & $\begin{array}{l}\text { (epi)catechin containing B-type PAC polymers } \\
\text { as well as their galloylated derivatives }\end{array}$ & $\begin{array}{l}\text { Montero et al. } \\
\text { (2013a) }\end{array}$ \\
\hline Online 2D chromatography & Malus spec & (epi)catechin containing B-type PAC polymers & $\begin{array}{l}\text { Montero et al. } \\
\text { (2013b) }\end{array}$ \\
\hline Online 2D chromatography & Aronia melanocarpa & $\begin{array}{l}\text { (epi)catechin and (epi)gallocatechin containing } \\
\text { PAC polymers, galloylated derivatives }\end{array}$ & $\begin{array}{l}\text { Brazdauskas et al. } \\
\text { (2016) }\end{array}$ \\
\hline Online 2D chromatography & Theobroma cacao & $\begin{array}{l}\text { (epi)catechin containing A- and B-type PAC } \\
\text { polymers, glycosylated PAC polymers }\end{array}$ & $\begin{array}{l}\text { Kalili and Villiers } \\
\text { (2013b) }\end{array}$ \\
\hline Online 2D chromatography & Vitis vinifera & $\begin{array}{l}\text { (epi)catechin containing PAC polymers, } \\
\text { galloylated derivatives }\end{array}$ & Kalili et al. (2013) \\
\hline \multirow[t]{3}{*}{$\begin{array}{l}\text { Online 2D chromatography coupled } \\
\text { with ABTS-assay }\end{array}$} & Camellia sinensis & $\begin{array}{l}\text { (epi)catechin and (epi)catechin gallate, } \\
\text { (epi)gallocatechin and (epi)gallocatechin } \\
\text { gallate }\end{array}$ & \multirow[t]{3}{*}{ Kalili et al. (2014) } \\
\hline & Vitis vinifera & $\begin{array}{l}\text { (epi)catechin containing B-type PAC polymers, } \\
\text { galloylated derivatives }\end{array}$ & \\
\hline & Theobroma cacao & $\begin{array}{l}\text { (epi)catechin containing A- and B-type PAC } \\
\text { polymers, PAC polymers }\end{array}$ & \\
\hline
\end{tabular}


Table 1 continued

\begin{tabular}{|c|c|c|c|}
\hline Methodology & Plant material & PAC found in the plant & References \\
\hline Online 2D chromatography & Malus spec & $\begin{array}{l}\text { (epi)catechin containing containing PAC } \\
\text { polymers }\end{array}$ & $\begin{array}{l}\text { Sommella et al. } \\
\text { (2017) }\end{array}$ \\
\hline Online 2D chromatography & Theobroma cacao & (epi)catechin containing B-type PAC polymers & $\begin{array}{l}\text { Toro-Uribe et al. } \\
\text { (2018) }\end{array}$ \\
\hline $\begin{array}{l}\text { Online 2D chromatography } \\
\text { optimization }\end{array}$ & $\begin{array}{l}\text { Isolated (epi)catechin } \\
\text { polymers }\end{array}$ & $\begin{array}{l}\text { Investigation of plant PAC composition was not } \\
\text { the focus of this work }\end{array}$ & $\begin{array}{l}\text { Muller et al. } \\
\text { (2018) }\end{array}$ \\
\hline Online $\mathrm{LC} \times \mathrm{LC} \times \mathrm{IMS}$ analysis & $\begin{array}{l}\text { Vitis vinifera } \\
\text { Castanea sativa } \\
\text { Aspalathus linearis }\end{array}$ & $\begin{array}{l}\text { Investigation of plant PAC composition was not } \\
\text { the focus of this work }\end{array}$ & $\begin{array}{l}\text { Venter et al. } \\
\text { (2018) }\end{array}$ \\
\hline MALDI-TOF Matrix Optimization & Onobrychis viciifolia & $\begin{array}{l}\text { (epi)catechin-,(epi)gallocatechin containing A- } \\
\text { and B-type PAC polymers, glycosylated } \\
\text { A-type PAC polymers }\end{array}$ & $\begin{array}{l}\text { Stringano et al. } \\
\text { (2011) }\end{array}$ \\
\hline MALDI-TOF/TOF & $\begin{array}{l}\text { Cinnamomum } \\
\text { zeylanicum }\end{array}$ & $\begin{array}{l}\text { (epi)catechin, (epi)catechingallate, } \\
\text { (epi)gallocatechin, and } \\
\text { (epi)afzelechin containing A- and B- type PAC } \\
\text { polymers }\end{array}$ & $\begin{array}{l}\text { Mateos-Martín } \\
\text { et al. (2012) }\end{array}$ \\
\hline MALDI-TOF/TOF & $\begin{array}{l}\text { Isolated (epi)catechin } \\
\text { polymers }\end{array}$ & $\begin{array}{l}\text { Investigation of plant PAC composition was not } \\
\text { the focus of this work }\end{array}$ & Rush et al. (2018) \\
\hline MALDI-TOF/TOF & Eugenia dysenterica & $\begin{array}{l}\text { (epi)catechin, (epi)catechingallate, } \\
\text { (epi)gallocatechin containing B-type PAC } \\
\text { polymers }\end{array}$ & Prado et al. (2014) \\
\hline MALDI-TOF/TOF & $\begin{array}{l}\text { Byrsonima } \\
\text { verbascifolia }\end{array}$ & $\begin{array}{l}\text { (epi)catechin-,(epi)gallocatechin containing A- } \\
\text { and B-type PAC polymers, galloylated } \\
\text { derivatives }\end{array}$ & $\begin{array}{l}\text { Saldanha et al. } \\
\text { (2016) }\end{array}$ \\
\hline PAC Fluorescence microscopy & $\begin{array}{l}\text { Vaccinium } \\
\text { macrocarpon }\end{array}$ & $\begin{array}{l}\text { Investigation of plant PAC composition was not } \\
\text { the focus of this work }\end{array}$ & $\begin{array}{l}\text { Feliciano et al. } \\
\text { (2015) }\end{array}$ \\
\hline MALDI Imaging & Fragaria $\times$ ananassa & $\begin{array}{l}\text { (epi)afzelechin and (epi)catechin containing } \\
\text { B-type PAC polymers }\end{array}$ & $\begin{array}{l}\text { Enomoto et al. } \\
\text { (2019) }\end{array}$ \\
\hline MALDI Imaging & Arachis hypogaea & $\begin{array}{l}\text { (epi)catechin containing A- and B-type PAC } \\
\text { polymers }\end{array}$ & $\begin{array}{l}\text { Enomoto and } \\
\text { Nirasawa (2020) }\end{array}$ \\
\hline PAC isotope analysis & $\begin{array}{l}\text { Vaccinium } \\
\text { macrocarpon }\end{array}$ & $\begin{array}{l}\text { (epi)catechin containing A- and B-type PAC } \\
\text { polymers }\end{array}$ & $\begin{array}{l}\text { Feliciano et al. } \\
\text { (2012) }\end{array}$ \\
\hline PAC isotope analysis & Vaccinium spec & $\begin{array}{l}\text { (epi)catechin containing A- and B-type PAC } \\
\text { polymers }\end{array}$ & $\begin{array}{l}\text { Esquivel- } \\
\text { Alvarado et al. } \\
\text { (2020) }\end{array}$ \\
\hline
\end{tabular}

secondary modified PAC of a distinct DP (Kalili and Villiers 2009). UV, fluorescence and MS detection can be used for the tentative identification of PAC. DP clusters up to DP 6 have been examined by these methods, followed also by investigation of the respective 2D fluorescence contour plots (Kalili and Villiers 2009). This procedure, combining the elution profiles of both chromatographic dimensions, turned out to be suitable for conclusive evaluation of the fingerprint for comparison of the respective PAC patterns obtained from different extract (Kalili and Villiers 2009). For example, in apple extract B-type proanthocyanidins, composed of only (epi)catechin could be identified. In cocoa samples additionally A-type procyanidins up to DP 6 and procyanidinglycosides up to DP 7 were found (Kalili and Villiers 2009).

The major advantage of $2 \mathrm{D}-\mathrm{LC}$ is the enhanced peak capacity, gained by the combination of two different stationary phases (Villiers et al. 2016). 
HILIC chromatography — with a gradient starting e.g., from acetonitrile to methanol/water-is principally suited to be used within the first dimension, not only because of the good separation capacity for distinct DP clusters. This mobile phase is also miscible with water and can be used for injection on a RP phase in the second dimension. Nevertheless, it is important to note, that the organic solvents from the first dimension exhibit high elution strength in the second dimension. For this reason, the injection volume should be reduced to quite low amounts, to minimize peak broadening due to strong elution activity of the first dimension eluent in the second dimension. It is important to note, that the number of separated isomers per DP is decreasing with increasing DP due to the lower resolution on RP phase for higher DP polymers (Kalili and Villiers 2009).

Similar LC $\times$ LC protocols have been used for the analysis of polyphenols, including PAC, phenolic acids and flavonols in extracts from green and black tea (Kalili and Villiers 2010; Scoparo et al. 2012). Tuominen et al. used an offline Diol HILIC $\times$ RP 2D chromatography approach with UV and (-)ESI-TOFMS/MS to analyze the PAC pattern from different organs of Geranium sylvaticum. PAC consisting of a variable number of (epi)catechin and (epi)gallocatechin units were identified in varying quantities in all organs (Tuominen and Karonen 2018).

Online 2D chromatography Montero et al. (2013a, b) enhanced the 2D chromatography system by developing an online $2 \mathrm{D}$ approach using again a diol HILIC phase in the first and a RP18 phase in the second dimension (Montero et al. 2013a). The first dimension chromatography runs at rather low flow rates with long gradients to guarantee the transfer of single fractions to the second dimension. Both dimensions were linked by a 10-port-2-position switching valve to two identical sample loops to transport the fractions from the first to the second dimension. The flow rate of the second dimension had to be high, coupled with a very short gradient to allow the injection of the following first dimension fraction. This leads on the one hand to a short total run time of around one hour, but on the other hand the quality of separation of single DP clusters in the second dimension had considerably declined, especially for PAC with DP $>4$ (Montero et al. 2013a). To reduce the elution strength from the first dimension mobile phase on the separation of the second dimension, the first dimension eluent was mixed with the starting condition solvent of the second dimension in a sample loop of the switching valve (Montero et al. 2013a). Detection and tentative identification of grape seed PAC (including galloylated entities) up to DP 7 was performed by UV and (-)ESI-MS/MS, and the chromatographic results obtained were displayed in a 2D HILIC $\times$ RP plot (Montero et al. 2013a).

In general, online $2 \mathrm{D}$ chromatography is very complex and needs a precise regulation and adaption of the parameters of the single components. Once established, such systems can be promising tools for PAC analysis, as they provide not only an overview on the DP cluster distribution but gain also detailed insights into the PAC composition with regard to building blocks, interflavan linkages, and secondary modifications (Montero et al. 2013a). The applicability of such methods for comparing different PAC extracts has been shown for the analytical characterization of PAC from different apple cultivars (Montero et al. 2013b) and later on also for polyphenols from black chokeberries (Brazdauskas et al. 2016).

Systematic comparison of on-line, off-line and stop-flow comprehensive diol HILIC $\times$ RP chromatography for PAC analysis from cocoa seeds has been evaluated by Kalili and Villiers (2013a, b). The stop flow 2D chromatography is a complex alternative to on-line and of-line 2D-LC. Stop flow 2D-LC can be seen as a combination of elements from the other two approaches. It is characterized by an online $2 \mathrm{D}$ chromatography, where the flow from the first dimension chromatography is stopped, as long as the second dimension chromatography is in progress. This enables longer gradients and therefore a better quality of the second dimension separation (Kalili and Villiers 2013a, b). Within the systematically comparison of the three protocols by Kalili and Villiers $(2013 a, b)$ data sets have been evaluated with regard to the total resolving power (peak capacity) and analysis time. Online 2D chromatography offers short analysis times, high reproducibility and automated and fast throughput, but exerts the lowest peak capacity of all three investigated methods, due to the fast second dimension separation (Kalili and Villiers 2013a, b). Furthermore, the complex setup, requiring a 10-port2-position high pressure switching valve and a precise adjustment of the respective parameters is not realizable in most standard labs (Kalili and Villiers 
2013a, b). In contrast, offline 2D chromatography offers a higher peak capacity and is easier applicable in analytical routine, but analysis time is considerably higher, single steps can hardly be automated, and first dimension fractions can be contaminated when prepared for the second dimension run (Kalili and Villiers 2013a, b). The stop-flow chromatography is considered to be a suitable and promising alternative to offline 2D chromatography of PAC, as the peak broadening in the first dimension, which is theoretically possible while waiting for the end of the respective second dimension run, was not significantly observed. Furthermore, stop flow analysis can be automated and sample contamination is avoided due to the closed system (Kalili and Villiers 2013a, b). Therefore, online 2D methods are better suited for screening and offline and stop flow methods are preferred for detailed analysis of PAC containing extracts. Generally, it is important to note, that the two orthogonal chromatographic principles in 2D-LC have to be individually adapted to the given technical conditions to maximise the respective outcome (Kalili and Villiers 2013a, b).

In a subsequent study, Kalili et al. (2013) transferred the online diol HILIC $\times$ RP-LC method with fluorescence and ESI-TOF-MS detection to the analysis of PAC from grape seeds, presenting an optimization of the method from Montero et al. (2013a, b) (Kalili et al. 2013). Chromatographic and MS data from 2D-LC analysis can additionally be displayed in a 2D contour plot, where either fluorescence data or MS data (e.g. total ion chromatogram) are added as a third dimension to form heat-map like plots (Kalili et al. 2013). LC $\times$ LC and HR-MS data revealed the presence of galloylated PAC up to DP 8 and confirms, that the online LC $\times$ LC approach gains deep insights into PAC composition, based on only one comprehensive analysis (Kalili et al. 2013).

To connect the ability of detailed examination of the PAC composition of a samples to the investigation of the radical scavenging activity of single polyphenolic compounds, 2D-LC analysis have been connected online to an ABTS-radical scavenging assay by Kalili et al. (2014). Although online coupling to LCABTS is known for one dimensional measurements, this 2D approach offers the possibility of a more detailed elucidation of the radical scavenging activity of single compounds (Kalili et al. 2014). After the diol HILIC $\times$ RP-LC with UV detection, the eluent was conducted to a reaction coil, where the interaction of the single polyphenol with the ABTS reagent takes place. The redox product was detected by UV detection $(\lambda=414 \mathrm{~nm})$. Peak identification can be performed by the respective retention times, UV spectra and MS data (Kalili et al. 2014). Therefore, a correlation of structure and antioxidative activity could be revealed by a single analysis (Kalili et al. 2014). In future, further enzymatic reactions in the interaction provide an interesting screening tool for complex PAC samples in order to investigate in detail structure-functionality by hyphenated 2D-LCbioassay.

Sommella et al. (2017) improved 2D HILIC $\times$ RP chromatography of apple polyphenols with respect to higher peak capacity and increased sensitivity by installing two short RP pre-column cartridges between the two dimensions instead of two sample loops (Sommella et al. 2017). This helps for focussing the analytes from the first dimension fraction prior to the injection into the second dimension (Sommella et al. 2017). Peak identification was performed by subsequent UV-(-)ESI-TOF-MS/MS analysis and results were presented in 2D and 3D UV and MS contour plots (Sommella et al. 2017).

Two more approaches published recently tried to optimize the 2D chromatography as well. The first approach, called "focusing-modulated", used diol HILIC $\times$ RP coupled with PDA and (-)ESI-MS/MS detection and short RP trapping columns as mentioned above; additionally a make-up flow has been integrated with the initial solvent composition of the second dimension, which was installed between the first dimension and the interface (Toro-Uribe et al. 2018). This regulates the solvent strength to overcome the problem of solvent incompatibilities of the two dimensions, actively modulating the focus of the 1D peaks (Toro-Uribe et al. 2018). Consequently, first dimension peaks are sharper before injection into the second dimension, leading to higher peak capacities and increased resolving power (Toro-Uribe et al. 2018). The benefits of this system have been shown for procyanidins up to DP 12 from green cocoa bean extract (Toro-Uribe et al. 2018). After extensive predictive optimization, Muller et al. (2018) came to similar results, recommending a make-up flow and a flow split between the first and the second dimension to improve the separation (Muller et al. 2018). Venter et al. (2018) added ion mobility spectrometry MS 
(IMS-MS) as a third dimension to the $\mathrm{LC} \times \mathrm{LC}$ system and created a amid HILIC $\times$ RP-LC-UV $\times$ IMS-MS analysis for the analysis of polyphenols from chestnut, red wine, grape seed and rooibos tea samples. IMS-MS is based on the principle that ions pass an electric field in a gas filled drift tube before reaching the mass analyser. This mechanism separates ions by their size, shape, stereochemistry and charge. IMS enables the identification of isomers, which can hardly be separated by LC $\times$ LC. These isomers could be rotational conformers or prototropic ions, which is a subtype of tautomerism, where protons are attached to different parts of the molecules (Kuhnert et al. 2015). Although LC-IMS-MS provides in total an enhanced peak capacity and separation power, the presented system is up to now not suited for higher mass range measurements and therefore 3D analysis could not yet improve PAC analysis compared to 2D LC analysis with simple MS detection (Venter et al. 2018).

Two-dimensional LC $\times$ LC techniques are promising tools in PAC analysis. Due to the enhanced chromatographic separation of DP clusters using HILIC mode in the first and RP mode in the second dimension information regarding the structural composition of clusters is extensively increased within only one chromatographic run. As well as in onedimensional LC-MS techniques, MS/MS fragments can be used for polymer identification and sequencing. Nevertheless, the quality of chromatographic separation is decreasing with increasing DP, due to the limitation of the HILIC phase and the increasing structural complexity of PAC polymers. As technical requirements are significant, the two-dimensional LC $\times$ LC protocols are still rather experimental approaches.

\section{MALDI-TOF mass spectrometry}

\section{Investigation of matrices for optimized PAC analysis}

Stringano et al. (2011) investigated in detail the impact of different matrices on the MALDI-TOF mass spectra for PAC analysis, indicating that the quality of the obtained spectra highly depends on the matrix itself, but also on the concentration of the respective matrix solution. Variations across these parameters result in differences in the detection of PAC with higher DP, but also concerning PAC series, being present in the plant extracts only in lower amounts (e.g. glycosylated
PAC). Interestingly, a mixture of DHB and $\mathrm{HMB}$ at a ratio of $9: 1(\mathrm{w} / \mathrm{w})$ in a concentration of $20 \mu \mathrm{g} / \mu \mathrm{L}$, dissolved in acetonitrile/water $(7: 3 v / v)$ with $\mathrm{Na}^{+}$ addition as cationizing agent leads to best results in the analysis of PAC from Sainfoin (Onobrychis viciifolia) (Stringano et al. 2011).

\section{MADLI-TOF/TOF}

In the majority of reports, dealing with PAC analysis by MALDI-TOF, evaluation has been performed in the positive ion mode without any fragmentation reactions (Monagas et al. 2010). Behrens et al. (2003) performed first experiments with MS-fragmentation of PAC from hydroacetonic extracts of leaves/needles from willow (Salix alba), spruce (Picea abies), beech (Fagus sylvatica) and lime (Tilia cordata). Using Post Source Decay (PSD) within the MALDI-TOF analysis in the positive mode, detailed fragmentation was achieved, resulting in the basic understanding of PAC fragmentation mechanisms, especially related to the interflavan cleavage (Behrens et al. 2003). Later on Marteos-Martin et al. (2012) introduced collision induced dissociation (CID) for PAC analysis from a hydroacetonic cinnamon extract. An argon filled CID chamber was used for fragmentation and ions were analyzed by tandem time of flight (MALDI-TOF/ TOF) mass spectrometry in the positive ion mode. It is interesting, that the fragmentation pathways, deduced from the respective fragment spectra, seem to correspond to the fragmentation pathways known from ESI-MS/MS experiments, including quinone methide (QM, or interflavan) cleavage, heterocyclic ring fission (HRF) and retro-Diels-Alder fission (RDA). With the help of these fragmentation spectra an identification of building blocks, interflavan linkages and secondary modifications e.g., galloylation of PAC is possible (Gu et al. 2003; Mateos-Martín et al. 2012). Similar MALDI-TOF/TOF experiments in the positive ion mode have been performed by Prado et al. (2014) and Saldanha et al. (2016) to analyse an aqueous extract from Eugenia dysenterica and a methanolic extract from Byrsonima verbascifolia, respectively (Prado et al. 2014; Saldanha et al. 2016).

In contrast, Rush et al. (2018) performed detailed studies on MALDI-TOF/TOF ionization and fragmentation behaviour of 20 isolated PAC compounds in the negative ion mode (Rush et al. 2018). The advantage of the negative mode ionisation in comparison to 
positive can be seen in the fact, that mainly deprotonated molecular ions with $[\mathrm{M}-\mathrm{H}]^{-}$are observed in the spectra and no positive ions of different cation adducts occur. As seen in the MALDI-TOF/TOF in the positive mode, typical RDA, HRF and QM fissions were observed, but the benzofuran forming fission (BFF), appearing especially after ESI-MS/MS ionization, has not been detected (Rush et al. 2018). The obtained fragmentation spectra were suitable for detailed sequencing of the analyzed PAC chains, based on the heterolytic and characteristic cleavage. Therefore, complex PAC types, like e.g. A-type and B-type PAC, as well as PAC with different hydroxylation patterns and secondary modifications can be identified preferably by MALDI-TOF/TOF in the negative ion mode (Rush et al. 2018).

\section{MALDI-TOF imaging}

A new and interesting approach for preparation and analytical characterisation of fluorescence labelled PAC was introduced by Feliciano et al. (2015). In order to investigate the interaction of PAC with extraintestinal pathogenic Escherichia coli, PAC (a fraction of polymeric PAC isolated from a Sephadex LH-20 stationary phase after elution with acetone-water $4: 1$ $(v / v))$ from a hydroacetonic Cranberry fruit extract (Vaccinium macrocarpon)) were labelled with the fluorophore 5-([4,6-dichlorotriazin-2-yl]amino)fluorescein (DTAF) and subsequently analyzed by fluorescence microscopy (Feliciano et al. 2015). Although PAC are active for fluorescence itself, analysis via fluorescence microscopy is not possible in this genuine form, as the excitation and emission wavelength are in the ultraviolet region at $\lambda_{\mathrm{ex}}=276 \mathrm{~nm}$ resp. $\lambda_{\mathrm{em}-}$ $=310 \mathrm{~nm}$. Therefore, coupling with an additional fluorophore is necessary (Feliciano et al. 2015). MALDI-TOF-MS indicated the linkage of the PAC with DTAF via the phenolic hydroxyl groups of the A and C-rings of the flavan-3-ol units. They are supposed to react with the chlorine atoms of the dichlorotriazin moiety in a nucleophilic-aromatic substitution and will form a covalent ether bond, in alkaline aqueous solution ( $\mathrm{pH}$ 10.5, with triethylamine). The $\mathrm{pH}$ should not be higher, as degradation reactions may occur at both species, PAC and DTAF. The success of the reaction was proven by HPLC on RP18 stationary phase, by the observation that the PAC hump is shifting to higher retention times, due to the more lipophilic features of the labelled PAC. Single- and double-labelled PAC from DP 2 to 11 were detected with MALDI-TOF/TOF-MS (Feliciano et al. 2015). Bright field and fluorescence microscopy revealed that both, unlabelled as well as labelled PAC, lead to an agglutination of extra-intestinal pathogenic E. coli. The agglutination again was monitored in detail by fluorescence microscopy, indicating, that this technique is very promising for analysis of interactions between PAC and pathogens or host cells (Feliciano et al. 2015).

In addition to the previously described approach of visualizing PAC by use of specific fluorescence markers, Enomoto et al. (2019) recently reported a further interesting protocol. By use of MALDI mass spectrometry imaging (MALDI-MSI) technique, PAC were identified and localized in sections of ripe strawberries (Fragaria $\times$ ananassa) (Enomoto et al. 2019). Figure 5 displays optical images of strawberry tissue sections before MALDI-MS as well as the impressive detection and localisation of mono- and oligomeric PAC in the fruit tissues (Figure was taken with kind permission of Dr. Enomoto from his Open Access Publication (Enomoto et al. 2019)). MALDI measurements were performed in the negative ion mode, in order to avoid the formation of cationic adducts. 1,5-Diaminonaphthalene (DAN) achieved the highest signal intensities and was chosen as optimized matrix. Longitudinal Sects. $(100 \mu \mathrm{m})$ were prepared using carboxymethyl cellulose cryo embedding which were subsequently analyzed by MALDIMSI. In general, the following flavan-3-ols and PAC were identified: (epi)afzelechin and (epi)catechin monomers, B-type PAC with only (epi)catechin as building block from DP 2 to 4 and B-type PAC with one (epi)afzelechin unit instead of (epi)catechin at DP 2 and 3 (Enomoto et al. 2019). Ion identity was verified by MALDI-TOF/TOF fragmentation analysis, based on the common fragmentation pathways QM, RDA and HRF. For MALDI-MSI, the optical image was overlaid with the respective extracted ion images of distinct PAC ions. The intensity of the MS signals was expressed by a heat map presentation (Enomoto et al. 2019). It is important to note, that some in-source QM fragmentation products have been recognized, which may lead to misinterpretation of the MS-spectra (Enomoto et al. 2019). Interestingly, PAC could mainly be found in the epidermis of the fruit, the vascular bundles and in the calyx. Detailed analysis of 

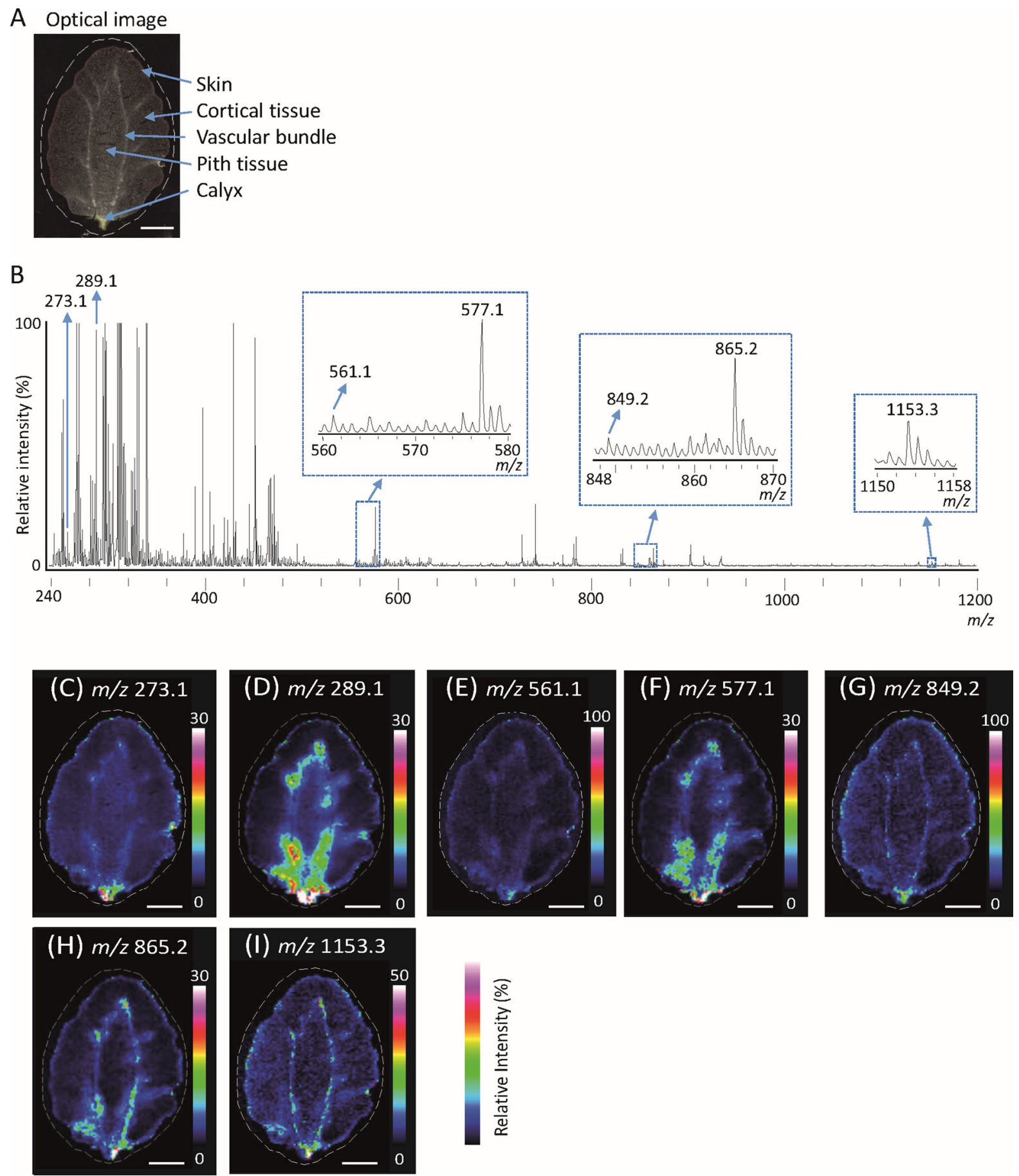

Fig. 5 MALDI-MS imaging of strawberry fruit sections. a Optical image of a strawberry fruit section before MALDIMSI analysis. Dotted lines indicate the analysed region. b Mass spectrum obtained from the strawberry fruit section. The $\mathrm{m} / \mathrm{z}$, values indicate that the peaks were possibly attributable to flavan-3-ols. The relative intensity of the strongest $\mathrm{m} / \mathrm{z}, 289.1$ in the peaks with potential compounds of (epi)catechin was defined as $95 \%$. Representative ion images at $\mathrm{m} / \mathrm{z}$ c 273.1, d 289.1, e 561.1, f 577.1, g 849.2, h 865.2, and i 1153.3. Scale bar $=5 \mathrm{~mm}$. (Figure and Legend to Figure with kind permission of Dr. Enomoto from his Open Access Publication (Enomoto et al. 2019)) 
signal intensities and ion location revealed that the procyanidins are significantly higher concentrated in vascular bundles than in the skin, whereas propelargonidins are equally distributed in both tissues (Enomoto et al. 2019). This technique is a promising method to get a deeper understanding of PAC biosynthesis, depletion and function (Enomoto et al. 2019). A follow-up study indicated (epi)catechin monomers, as well as A- and B-type PAC from DP 2 to 4 to be present in the outer epidermis of the peanut (Arachis hypogea) testa, using the above described MALDI-MSI and MALDI-TOF/TOF protocol (Enomoto and Nirasawa 2020).

\section{Isotope analysis of MALDI-TOF data}

MALDI-TOF MS in the positive reflectron mode and subsequent deconvolution of the respective isotope patterns has been developed for determination of the ratio of A- and B-type PAC from Cranberry fruits (Vaccinium macrocarpon) by Feliciano et al. (2012).

The ether-like A-type linkage in PAC will result in a molecular weight $2 u$ less than the respective B-type PAC. Therefore, the MS spectra exhibits overlapping signals of A-type isotopologue to the respective B-type monoisotope, which can be calculated due to the natural abundances of the isotopologues. To include this effect in the determination of A- and B-type PAC ratio deconvolution, a MALDI-TOF MS validation has been performed by use of isolated procyanidin $\mathrm{A} 2$ and $\mathrm{B} 2$ in mixtures of different ratios and on the basis of the comparison of calculated and measured isotope patterns (Feliciano et al. 2012). From this, the ratios of A- and B-type PAC in the range from DP 2 to 11 had been determined by analysing the respective isotope patterns. In case of analysing PAC from Cranberry fruits, these investigations revealed, that the A-type PAC are the dominating class of PAC in the test samples (Feliciano 2012). Furthermore, the number of A-type linkages seems to increase with increasing DP as e.g., PAC DP 4 to DP 11 the percentage of PAC chains with three A-type linkages in the molecule is increasing from about $10 \%$ (DP4) to about $40 \%$ (DP11) (Feliciano et al. 2012). This methodology has recently been adapted for detailed investigation of PAC from three different tropical Vaccinium species, indicating that more than $74 \%$ of the PAC oligomers (DP 3 to 8) contain more than one A-type linkage (Esquivel-Alvarado et al. 2020). It has to be mentioned that MALDI TOF in the linear mode is not well suited for the detection of PAC oligo- and polymers with higher DP due to the low resolution, which does not provide enough information on the respective isotope patterns (Feliciano et al. 2012).

\section{Conclusion}

In summary, it is obvious that in the last decade LCMS and MALDI-TOF MS for PAC analysis has been developed extremely dynamic. Especially the introduction of 2D chromatographic methods and improved MS data processing impacts the PAC analysis fundamentally, as both methods are key player for the identification of so far unknown PAC series. These methods are also suited for fingerprint analysis of PAC containing plant extracts, leading to ab better understanding of PAC distribution in the plant kingdom and effects of PAC containing foods and medicines on human and animal health. Also the visualization of PAC in complex biological matrices by MALDI-TOF imaging opens the doors for manifold applications in biological science, as e.g. for the localization of PAC in plant tissues or further understanding of the relationship between PAC and epithelia. The use of MALDI-TOF/TOF MS in the negative ion mode can be useful for answering special analytical questions, which cannot solved by use of the classical LC-MS/MS protocols. Nevertheless, it is still a problem, that MALDI and ESI-MS signal intensity and detectability of PAC is decreasing with increasing DP, a phenomenon that limits especially identification of PAC series which are only present in a mixture at lower concentrations. Therefore, there is still potential for the development of LC or MS methods for the detection of high DP PAC polymers.

Authors contribution NS and AH wrote the manuscript. NS reviewed the literature, collected the data and assembled the MS.

Funding Open Access funding enabled and organized by Projekt DEAL. Only intramural grants from the University of Münster, Germany were used for preparation of the present manuscript.

Availability of data and material Not applicable. 


\section{Declarations}

Conflict of interest The authors declare no competing financial interests.

Open Access This article is licensed under a Creative Commons Attribution 4.0 International License, which permits use, sharing, adaptation, distribution and reproduction in any medium or format, as long as you give appropriate credit to the original author(s) and the source, provide a link to the Creative Commons licence, and indicate if changes were made. The images or other third party material in this article are included in the article's Creative Commons licence, unless indicated otherwise in a credit line to the material. If material is not included in the article's Creative Commons licence and your intended use is not permitted by statutory regulation or exceeds the permitted use, you will need to obtain permission directly from the copyright holder. To view a copy of this licence, visit http://creativecommons.org/licenses/by/4.0/.

\section{References}

Aerts RJ, Barry TN, McNabb WC (1999) Polyphenols and agriculture: beneficial effects of proanthocyanidins in forages. Agr Ecosyst Environ 75:1-12. https://doi.org/10. 1016/S0167-8809(99)00062-6

Anke J, Petereit F, Engelhardt C, Hensel A (2008) Procyanidins from Myrothamnus flabellifolia. Nat Prod Res 22:1237-1248. https://doi.org/10.1080/14786410701726343

Behrens A, Maie N, Knicker H, Kögel-Knabner I (2003) MALDI-TOF mass spectrometry and PSD fragmentation as means for the analysis of condensed tannins in plant leaves and needles. Phytochemistry 62:1159-1170. https:// doi.org/10.1016/s0031-9422(02)00660-x

Bianchi S, Kroslakova I, Janzon R, Mayer I, Saake B, Pichelin F (2015) Characterization of condensed tannins and carbohydrates in hot water bark extracts of European softwood species. Phytochemistry 120:53-61. https://doi.org/10. 1016/j.phytochem.2015.10.006

Brazdauskas T, Montero L, Venskutonis PR, Ibañez E, Herrero M (2016) Downstream valorization and comprehensive two-dimensional liquid chromatography-based chemical characterization of bioactives from black chokeberries (Aronia melanocarpa) pomace. J Chromatogr A 1468:126-135. https://doi.org/10.1016/j.chroma.2016.09. 033

Cacciola F, Jandera P, Mondello L (2007) Comparison of hightemperature gradient heart-cutting and comprehensive LC $\times$ LC systems for the separation of phenolic antioxidants. Chroma 66:661-667. https://doi.org/10.1365/s10337-0070379-3

Chai W-M, Shi Y, Feng H-L, Xu L, Xiang Z-H, Gao Y-S, Chen Q-X (2014) Structure characterization and anti-tyrosinase mechanism of polymeric proanthocyanidins fractionated from kiwifruit pericarp. J Agric Food Chem 62:6382-6389. https://doi.org/10.1021/jf501009v

de Villiers A, Venter P, Pasch H (2016) Recent advances and trends in the liquid-chromatography-mass spectrometry analysis of flavonoids. J Chromatogr A 1430:16-78. https://doi.org/10.1016/j.chroma.2015.11.077

Deng Y-T, Liang G, Shi Y, Li H-L, Zhang J, Mao X-M, Fu Q-R, Peng W-X, Chen Q-X, Shen D-Y (2016) Condensed tannins from Ficus altissima leaves: Structural, antioxidant, and antityrosinase properties. Process Biochem 51:1092-1099. https://doi.org/10.1016/j.procbio.2016.04.022

Dier TKF, Egele K, Fossog V, Hempelmann R, Volmer DA (2016) Enhanced mass defect filtering to simplify and classify complex mixtures of lignin degradation products. Anal Chem 88:1328-1335. https://doi.org/10.1021/acs. analchem.5b03790

Domínguez-Rodríguez G, Marina ML, Plaza M (2017) Strategies for the extraction and analysis of non-extractable polyphenols from plants. J Chromatogr A 1514:1-15. https://doi.org/10.1016/j.chroma.2017.07.066

Engström MT, Pälijärvi M, Fryganas C, Grabber JH, MuellerHarvey I, Salminen J-P (2014) Rapid qualitative and quantitative analyses of proanthocyanidin oligomers and polymers by UPLC-MS/MS. J Agric Food Chem 62:3390-3399. https://doi.org/10.1021/jf500745y

Enomoto H, Nirasawa T (2020) Localization of flavan-3-ol species in Peanut Testa by mass spectrometry imaging. Molecules. https://doi.org/10.3390/molecules25102373

Enomoto H, Takahashi S, Takeda S, Hatta H (2019) Distribution of flavan-3-ol species in ripe strawberry fruit revealed by matrix-assisted laser desorption/ionization-mass spectrometry imaging. Molecules. https://doi.org/10.3390/ molecules25010103

Erni F, Frei RW (1978) Two-dimensional column liquid chromatographic technique for resolution of complex mixtures. J Chromatogr A 149:561-569. https://doi.org/10.1016/ S0021-9673(00)81011-0

Esquivel-Alvarado D, Muñoz-Arrieta R, Alfaro-Viquez E, Madrigal-Carballo S, Krueger CG, Reed JD (2020) Composition of anthocyanins and proanthocyanidins in three tropical vaccinium species from costa rica. J Agric Food Chem 68:2872-2879. https://doi.org/10.1021/acs.jafc. 9b01451

Es-Safi N-E (2012) Mass spectroscopic methods for the characterization of flavonoid compounds. CBC 8:240-265. https://doi.org/10.2174/157340712802762456

European Pharmacopoiea 10.0 (2020) Gerbstoffe in pflanzlichen Drogen. Deutscher Apotheker Verlag, Stuttgart, Germany

Feliciano RP, Krueger CG, Shanmuganayagam D, Vestling MM, Reed JD (2012) Deconvolution of matrix-assisted laser desorption/ionization time-of-flight mass spectrometry isotope patterns to determine ratios of A-type to B-type interflavan bonds in cranberry proanthocyanidins. Food Chem 135:1485-1493. https://doi.org/10.1016/j. foodchem.2012.05.102

Feliciano RP, Heintz JA, Krueger CG, Vestling MM, Reed JD (2015) Fluorescent labeling of cranberry proanthocyanidins with 5-(4,6-dichlorotriazin-2-ylamino)fluorescein (DTAF). Food Chem 166:337-345. https://doi.org/10. 1016/j.foodchem.2014.06.031

Fouquet TNJ (2019) The Kendrick analysis for polymer mass spectrometry. J Mass Spectrom 54:933-947. https://doi. org/10.1002/jms.4480 
Frost S, Lerno LA, Zweigenbaum J, Heymann H, Ebeler SE (2018) Characterization of red wine proanthocyanidins using a putative proanthocyanidin database, amide hydrophilic interaction liquid chromatography (HILIC), and time-of-flight mass spectrometry. Molecules. https://doi. org/10.3390/molecules 23102687

Gao C, Cunningham DG, Liu H, Khoo C, Gu L (2018) Development of a thiolysis HPLC method for the analysis of procyanidins in cranberry products. J Agric Food Chem 66:2159-2167. https://doi.org/10.1021/acs.jafc.7b04625

Gescher K, Hensel A, Hafezi W, Derksen A, Kühn J (2011) Oligomeric proanthocyanidins from Rumex acetosa L. inhibit the attachment of herpes simplex virus type- 1 . Antiviral Res 89:9-18. https://doi.org/10.1016/j.antiviral. 2010.10.007

Graham HD (1992) Stabilization of the Prussian blue color in the determination of polyphenols. J Agric Food Chem 40:801-805. https://doi.org/10.1021/jf00017a018

Gu L, Kelm MA, Hammerstone JF, Zhang Z, Beecher G, Holden J, Haytowitz D, Prior RL (2003) Liquid chromatographic/electrospray ionization mass spectrometric studies of proanthocyanidins in foods. J Mass Spectrom 38:1272-1280. https://doi.org/10.1002/jms.541

Gujer R, Magnolato D, Self R (1986) Glucosylated flavonoids and other phenolic compounds from sorghum. Phytochemistry 25:1431-1436. https://doi.org/10.1016/S00319422(00)81304-7

Guyot S, Doco T, Souquet J-M, Moutounet M, Drilleau J-F (1997) Characterization of highly polymerized procyanidins in cider apple (Malus sylvestris var. kermerrien) skin and pulp. Phytochemistry 44:351-357. https://doi.org/10. 1016/S0031-9422(96)00480-3

Guyot S, Marnet N, Drilleau J (2001) Thiolysis-HPLC characterization of apple procyanidins covering a large range of polymerization states. J Agric Food Chem 49:14-20. https://doi.org/10.1021/jf000814z

Halver J, Wenzel K, Sendker J, Carrillo García C, Erdelmeier CAJ, Willems E, Mercola M, Symma N, Könemann S, Koch E, Hensel A, Schade D (2019) Crataegus extract WS ${ }^{\circledR} 1442$ stimulates cardiomyogenesis and angiogenesis from stem cells: a possible new pharmacology for hawthorn? Front Pharmacol 10:1357. https://doi.org/10.3389/ fphar.2019.01357

Hammerstone JF, Lazarus SA, Mitchell AE, Rucker R, Schmitz HH (1999) Identification of procyanidins in cocoa (Theobroma cacao) and chocolate using high-performance liquid chromatography/mass spectrometry. J Agric Food Chem 47:490-496. https://doi.org/10.1021/jf980760h

Hammerstone JF, Lazarus SA, Schmitz HH (2000) Procyanidin content and variation in some commonly consumed foods. J Nutr 130:2086S-S2092. https://doi.org/10.1093/jn/130.8. $2086 \mathrm{~S}$

Hellenbrand N, Sendker J, Lechtenberg M, Petereit F, Hensel A (2015a) Isolation and quantification of oligomeric and polymeric procyanidins in leaves and flowers of Hawthorn (Crataegus spp.). Fitoterapia 104:14-22. https://doi.org/ 10.1016/j.fitote.2015.04.010

Hellenbrand N, Lechtenberg M, Petereit F, Sendker J, Hensel A (2015b) Isolation and quantification of oligomeric and polymeric procyanidins in the aerial parts of St. John's
Wort (Hypericum perforatum). Planta Med 81:1175-1181. https://doi.org/10.1055/s-0035-1545916

Hemström P, Irgum K (2006) Hydrophilic interaction chromatography. J Sep Sci 29:1784-1821. https://doi.org/10. 1002/jssc.200600199

Hughey CA, Hendrickson CL, Rodgers RP, Marshall AG, Qian K (2001) Kendrick mass defect spectrum: a compact visual analysis for ultrahigh-resolution broadband mass spectra. Anal Chem 73:4676-4681. https://doi.org/10.1021/ ac010560w

Hümmer W, Schreier P (2008) Analysis of proanthocyanidins. Mol Nutr Food Res 52:1381-1398. https://doi.org/10. 1002/mnfr.200700463

Jorgensen EM, Marin AB, Kennedy JA (2004) Analysis of the oxidative degradation of proanthocyanidins under basic conditions. J Agric Food Chem 52:2292-2296. https://doi. org/10.1021/jf035311i

Kalili KM, de Villiers A (2009) Off-line comprehensive 2-dimensional hydrophilic interaction $\mathrm{x}$ reversed phase liquid chromatography analysis of procyanidins. J Chromatogr A 1216:6274-6284. https://doi.org/10.1016/j.chroma.2009. 06.071

Kalili KM, de Villiers A (2010) Off-line comprehensive twodimensional hydrophilic interaction $\mathrm{x}$ reversed phase liquid chromatographic analysis of green tea phenolics. J Sep Sci 33:853-863. https://doi.org/10.1002/jssc.200900673

Kalili KM, de Villiers A (2013a) Systematic optimisation and evaluation of on-line, off-line and stop-flow comprehensive hydrophilic interaction chromatography $\times$ reversed phase liquid chromatographic analysis of procyanidins, part I: theoretical considerations. J Chromatogr A 1289:58-68. https://doi.org/10.1016/j.chroma.2013.03. 008

Kalili KM, de Villiers A (2013b) Systematic optimisation and evaluation of on-line, off-line and stop-flow comprehensive hydrophilic interaction chromatography $\times$ reversed phase liquid chromatographic analysis of procyanidins. Part II: application to cocoa procyanidins. J Chromatogr A 1289:69-79. https://doi.org/10.1016/j.chroma.2013.03. 009

Kalili KM, Vestner J, Stander MA, de Villiers A (2013) Toward unraveling grape tannin composition: application of online hydrophilic interaction chromatography $\times$ reversed-phase liquid chromatography-time-of-flight mass spectrometry for grape seed analysis. Anal Chem 85:9107-9115. https:// doi.org/10.1021/ac401896r

Kalili KM, de Smet S, van Hoeylandt T, Lynen F, de Villiers A (2014) Comprehensive two-dimensional liquid chromatography coupled to the ABTS radical scavenging assay: a powerful method for the analysis of phenolic antioxidants. Anal Bioanal Chem 406:4233-4242. https:// doi.org/10.1007/s00216-014-7847-z

Kawakami W, Oshima A, Yanase E (2018) Structural characterization of proanthocyanidins from adzuki seed coat. Food Chem 239:1110-1116. https://doi.org/10.1016/j. foodchem.2017.07.001

Kelm MA, Hammerstone JF, Schmitz HH (2005) Identification and quantitation of flavanols and proanthocyanidins in foods: how good are the datas? Clin Dev Immunol 12:35-41. https://doi.org/10.1080/ 10446670410001722177 
Kelm MA, Johnson JC, Robbins RJ, Hammerstone JF, Schmitz $\mathrm{HH}$ (2006) High-performance liquid chromatography separation and purification of cacao (Theobroma cacao L.) procyanidins according to degree of polymerization using a diol stationary phase. J Agric Food Chem 54:1571-1576. https://doi.org/10.1021/jf0525941

Kendrick E (1963) A mass scale based on CH $2=14.0000$ for high resolution mass spectrometry of organic compounds. Anal Chem 35:2146-2154. https://doi.org/10.1021/ ac60206a048

Kennedy JA, Jones GP (2001) Analysis of proanthocyanidin cleavage products following acid-catalysis in the presence of excess phloroglucinol. J Agric Food Chem 49:1740-1746. https://doi.org/10.1021/jf001030o

Kimura H, Ogawa S, Akihiro T, Yokota K (2011) Structural analysis of A-type or B-type highly polymeric proanthocyanidins by thiolytic degradation and the implication in their inhibitory effects on pancreatic lipase. J Chromatogr A 1218:7704-7712. https://doi.org/10.1016/j.chroma. 2011.07.024

Koupai-Abyazani MR, McCallum J, Bohm BA (1992) Identification of the constituent flavanoid units in sainfoin proanthocyanidins by reversed-phase high-performance liquid chromatography. J Chromatogr A 594:117-123. https://doi.org/10.1016/0021-9673(92)80319-P

Kuhnert N (2010) Unraveling the structure of the black tea thearubigins. Arch Biochem Biophys 501:37-51. https:// doi.org/10.1016/j.abb.2010.04.013

Kuhnert N, Dairpoosh F, Yassin G, Golon A, Jaiswal R (2013) What is under the hump? Mass spectrometry based analysis of complex mixtures in processed food-lessons from the characterisation of black tea thearubigins, coffee melanoidines and caramel. Food Funct 4:1130-1147. https://doi.org/10.1039/c3fo30385c

Kuhnert N, Yassin GH, Jaiswal R, Matei MF, Grün CH (2015) Differentiation of prototropic ions in regioisomeric caffeoyl quinic acids by electrospray ion mobility mass spectrometry. Rapid Commun Mass Spectrom 29:675-680. https://doi.org/10.1002/rcm.7151

Lazarus SA, Adamson GE, Hammerstone JF, Schmitz HH (1999) High-performance liquid Chromatography/Mass spectrometry analysis of proanthocyanidins in foods and beverages. J Agric Food Chem 47:3693-3701. https://doi. org/10.1021/jf9813642

Li H-J, Deinzer ML (2007) Tandem mass spectrometry for sequencing proanthocyanidins. Anal Chem 79:1739-1748. https://doi.org/10.1021/ac061823v

Löhr G, Beikler T, Podbielski A, Standar K, Redanz S, Hensel A (2011) Polyphenols from Myrothamnus flabellifolia Welw. inhibit in vitro adhesion of Porphyromonas gingivalis and exert anti-inflammatory cytoprotective effects in $\mathrm{KB}$ cells. J Clin Periodontol 38:457-469. https://doi.org/10.1111/j. 1600-051X.2010.01654.x

Luca SV, Macovei I, Bujor A, Miron A, Skalicka-Woźniak K, Aprotosoaie AC, Trifan A (2020) Bioactivity of dietary polyphenols: the role of metabolites. Crit Rev Food Sci Nutr 60:626-659. https://doi.org/10.1080/10408398.2018. 1546669

Mateos-Martín ML, Fuguet E, Quero C, Pérez-Jiménez J, Torres JL (2012) New identification of proanthocyanidins in cinnamon (Cinnamomum zeylanicum L.) using MALDI-TOF/
TOF mass spectrometry. Anal Bioanal Chem 402:1327-1336. https://doi.org/10.1007/s00216-0115557-3

Monagas M, Quintanilla-López JE, Gómez-Cordovés C, Bartolomé B, Lebrón-Aguilar R (2010) MALDI-TOF MS analysis of plant proanthocyanidins. J Pharm Biomed Anal 51:358-372. https://doi.org/10.1016/j.jpba.2009.03.035

Montero L, Herrero M, Prodanov M, Ibáñez E, Cifuentes A (2013a) Characterization of grape seed procyanidins by comprehensive two-dimensional hydrophilic interaction $x$ reversed phase liquid chromatography coupled to diode array detection and tandem mass spectrometry. Anal Bioanal Chem 405:4627-4638. https://doi.org/10.1007/ s00216-012-6567-5

Montero L, Herrero M, Ibáñez E, Cifuentes A (2013b) Profiling of phenolic compounds from different apple varieties using comprehensive two-dimensional liquid chromatography. J Chromatogr A 1313:275-283. https://doi.org/10.1016/j. chroma.2013.06.015

Motilva M-J, Serra A, Macià A (2013) Analysis of food polyphenols by ultra high-performance liquid chromatography coupled to mass spectrometry: an overview. J Chromatogr A 1292:66-82. https://doi.org/10.1016/j.chroma. 2013.01.012

Muller M, Tredoux AGJ, de Villiers A (2018) Predictive kinetic optimisation of hydrophilic interaction chromatography $\times$ reversed phase liquid chromatography separations: experimental verification and application to phenolic analysis. J Chromatogr A 1571:107-120. https://doi.org/10.1016/j. chroma.2018.08.004

Neilson AP, O'Keefe SF, Bolling BW (2016) High-Molecularweight proanthocyanidins in foods: overcoming analytical challenges in pursuit of novel dietary bioactive components. Annu Rev Food Sci Technol 7:43-64. https://doi. org/10.1146/annurev-food-022814-015604

Neto CC, Penndorf KA, Feldman M, Meron-Sudai S, ZakayRones Z, Steinberg D, Fridman M, Kashman Y, Ginsburg I, Ofek I, Weiss EI (2017) Characterization of non-dialyzable constituents from cranberry juice that inhibit adhesion, coaggregation and biofilm formation by oral bacteria. Food Funct 8:1955-1965. https://doi.org/10.1039/c7fo00109f

Nonaka G, Kawahara O, Nishioka I (1982) Tannins and related compounds. VIII. A new type of proanthocyanidin, cinchonains IIa and IIb from Cinchona succirubra. (2). Chem Pharm Bull 30:4277-4282. https://doi.org/10.1248/cpb.30. 4277

Nonaka G, Kawahara O, Nishioka I (1983) Tannins and related compounds. XV. A new class of dimeric flavan-3-ol gallates, theasinensins $\mathrm{A}$ and $\mathrm{B}$, and proanthocyanidin gallates from green tea leaf. (1). Chem Pharm Bull 31:3906-3914. https://doi.org/10.1248/cpb.31.3906

Ohnishi-Kameyama M, Yanagida A, Kanda T, Nagata T (1997) Identification of catechin oligomers from apple (Malus pumila cv. Fuji) in matrix-assisted laser desorption/ionization time-of-flight mass spectrometry and fast-atom bombardment mass spectrometry. Rapid Commun Mass Spectrom 11:31-36. https://doi.org/10.1002/(SICI)10970231(19970115)11:1\%3c31:AID-RCM784\%3e3.0.CO;2$\mathrm{T}$

Oliveira J, Alhinho da Silva M, Teixeira N, de Freitas V, Salas E (2015) Screening of anthocyanins and anthocyanin-derived 
pigments in red wine grape pomace using LC-DAD/MS and MALDI-TOF techniques. J Agric Food Chem 63:7636-7644. https://doi.org/10.1021/acs.jafc.5b00256

Ou K, Gu L (2014) Absorption and metabolism of proanthocyanidins. J Funct Foods 7:43-53. https://doi.org/10.1016/ j.jff.2013.08.004

Pérez-Jiménez J, Torres JL (2012) Analysis of proanthocyanidins in almond blanch water by HPLC-ESI-QqQ-MS/MS and MALDI-TOF/TOF MS. Food Res Int 49:798-806. https://doi.org/10.1016/j.foodres.2012.09.005

Peter Constabel C, Yoshida K, Walker V (2014) Diverse ecological roles of plant tannins: plant defense and beyond. In: Romani A, Lattanzio V, Quideau S (eds) Recent advances in polyphenol research, vol 49. Wiley. Chichester, UK, pp 115-142

Petridis GK (2011) Tannins: Types, foods containing, and nutrition. Nova Science Publishers, Hauppauge, N.Y, Food science and technology

Pinaffi ACdC, Sampaio GR, Soares MJ, Shahidi F, de Camargo AC, Torres EAFS (2020) Insoluble-bound polyphenols released from guarana powder: inhibition of alpha-glucosidase and proanthocyanidin profile. Molecules. https:// doi.org/10.3390/molecules25030679

Prado LCdS, Silva DB, de Oliveira-Silva GL, Hiraki KRN, Canabrava HAN, Bispo-da-Silva LB (2014) The gastroprotective effects of Eugenia dysenterica (Myrtaceae) leaf extract: the possible role of condensed tannins. Biol Pharm Bull 37:722-730. https://doi.org/10.1248/bpb.b13-00514

Price ML, Butler LG (1977) Rapid visual estimation and spectrophotometric determination of tannin content of sorghum grain. J Agric Food Chem 25:1268-1273. https://doi.org/ 10.1021/jf60214a034

Prieur C, Rigaud J, Cheynier V, Moutounet M (1994) Oligomeric and polymeric procyanidins from grape seeds. Phytochemistry 36:781-784. https://doi.org/10.1016/ S0031-9422(00)89817-9

Qi Y, Hempelmann R, Volmer DA (2016) Two-dimensional mass defect matrix plots for mapping genealogical links in mixtures of lignin depolymerisation products. Anal Bioanal Chem 408:4835-4843. https://doi.org/10.1007/s00216016-9598-5

Rauf A, Imran M, Abu-Izneid T, Iahtisham-Ul-Haq PS, Pan X, Naz S, Sanches Silva A, Saeed F, Rasul Suleria HA (2019) Proanthocyanidins: a comprehensive review. Biomed Pharmacother 116:108999. https://doi.org/10.1016/j. biopha.2019.108999

Reed JD, Krueger CG, Vestling MM (2005) MALDI-TOF mass spectrometry of oligomeric food polyphenols. Phytochemistry 66:2248-2263. https://doi.org/10.1016/j. phytochem.2005.05.015

Rigaud J, Perez-Ilzarbe J, Da Silva JMR, Cheynier V (1991) Micro method for the identification of proanthocyanidin using thiolysis monitored by high-performance liquid chromatography. J Chromatogr A 540:401-405. https:// doi.org/10.1016/S0021-9673(01)88830-0

Rigaud J, Escribano-Bailon MT, Prieur C, Souquet J-M, Cheynier V (1993) Normal-phase high-performance liquid chromatographic separation of procyanidins from cacao beans and grape seeds. J Chromatogr A 654:255-260. https://doi.org/10.1016/0021-9673(93)83368-3
Robbins RJ, Leonczak J, Li J, Johnson JC, Collins T, KwikUribe C, Schmitz HH (2012) Determination of flavanol and procyanidin (by degree of polymerization 1-10) content of chocolate, cocoa liquors, powder(s), and cocoa flavanol extracts by normal phase high-performance liquid chromatography: collaborative study. J AOAC Int 95:1153-1160. https://doi.org/10.5740/jaoacint.12-162

Rohr GE, Meier B, Sticher O (2000) Analysis of procyanidins. In: Bioactive Natural Products (Part B), vol 21. Elsevier, pp 497-570

Rue EA, Rush MD, van Breemen RB (2018) Procyanidins: a comprehensive review encompassing structure elucidation via mass spectrometry. Phytochem Rev 17:1-16. https:// doi.org/10.1007/s11101-017-9507-3

Rush MD, Rue EA, Wong A, Kowalski P, Glinski JA, van Breemen RB (2018) Rapid determination of procyanidins using MALDI-ToF/ToF mass spectrometry. J Agric Food Chem 66:11355-11361. https://doi.org/10.1021/acs.jafc. 8 b04258

Russo M, Cacciola F, Arena K, Mangraviti D, de Gara L, Dugo P, Mondello L (2020) Characterization of the polyphenolic fraction of pomegranate samples by comprehensive twodimensional liquid chromatography coupled to mass spectrometry detection. Nat Prod Res 34:39-45. https:// doi.org/10.1080/14786419.2018.1561690

Saldanha AA, de Siqueira JM, Castro AHF, de Azambuja Ribeiro RIM, de Oliveira FM, de Oliveira Lopes D, Pinto FCH, Silva DB, Soares AC (2016) Anti-inflammatory effects of the butanolic fraction of Byrsonima verbascifolia leaves: Mechanisms involving inhibition of tumor necrosis factor alpha, prostaglandin $\mathrm{E}(2)$ production and migration of polymorphonuclear leucocyte in vivo experimentation. Int Immunopharmacol 31:123-131. https://doi.org/10. 1016/j.intimp.2015.12.031

Salminen J-P (2018) Two-dimensional tannin fingerprints by liquid chromatography tandem mass spectrometry offer a new dimension to plant tannin analyses and help to visualize the tannin diversity in plants. J Agric Food Chem 66:9162-9171. https://doi.org/10.1021/acs.jafc.8b02115

Santos-Buelga C, Scalbert A (2000) Proanthocyanidins and tannin-like compounds - nature, occurrence, dietary intake and effects on nutrition and health. J Sci Food Agric 80:1094-1117. https://doi.org/10.1002/(SICI)10970010(20000515)80:7\%3c1094:AID-JSFA569\%3e3.0. $\mathrm{CO} ; 2-1$

Sarkar SK, Howarth RE (1976) Specificity of the vanillin test for flavanols. J Agric Food Chem 24:317-320. https://doi.org/ 10.1021/jf60204a041

Sato H, Nakamura S, Teramoto K, Sato T (2014) Structural characterization of polymers by MALDI spiral-TOF mass spectrometry combined with Kendrick mass defect analysis. J Am Soc Mass Spectrom 25:1346-1355. https://doi. org/10.1007/s13361-014-0915-y

Schmuch J, Beckert S, Brandt S, Löhr G, Hermann F, Schmidt TJ, Beikler T, Hensel A (2015) Extract from Rumex acetosa $\mathrm{L}$. for prophylaxis of periodontitis: inhibition of bacterial in vitro adhesion and of gingipains of Porphyromonas gingivalis by epicatechin-3-O- $(4 \beta \rightarrow 8)$-epicatechin-3-Ogallate (procyanidin-B2-Di-gallate). PLoS One 10:e120130. https://doi.org/10.1371/journal.pone. 0120130 
Schofield P, Mbugua DM, Pell AN (2001) Analysis of condensed tannins: a review. Anim Feed Sci Technol 91:21-40. https://doi.org/10.1016/S0377-8401(01)002280

Scoparo CT, de Souza LM, Dartora N, Sassaki GL, Gorin PAJ, Iacomini M (2012) Analysis of Camellia sinensis green and black teas via ultra high performance liquid chromatography assisted by liquid-liquid partition and two-dimensional liquid chromatography (size exclusion $\times$ reversed phase). J Chromatogr A 1222:29-37. https://doi.org/10.1016/j. chroma.2011.11.038

Sendker J, Petereit F, Lautenschläger M, Hellenbrand N, Hensel A (2013) Phenylpropanoid-substituted procyanidins and tentatively identified procyanidin glycosides from hawthorn (Crataegus spp.). Planta Med 79:45-51. https://doi. org/10.1055/s-0032-1327926

Sleno L (2012) The use of mass defect in modern mass spectrometry. J Mass Spectrom 47:226-236. https://doi.org/10. 1002/jms. 2953

Sommella E, Ismail OH, Pagano F, Pepe G, Ostacolo C, Mazzoccanti G, Russo M, Novellino E, Gasparrini F, Campiglia P (2017) Development of an improved online comprehensive hydrophilic interaction chromatography $x$ reversed-phase ultra-high-pressure liquid chromatography platform for complex multiclass polyphenolic sample analysis. J Sep Sci 40:2188-2197. https://doi.org/10.1002/ jssc. 201700134

Stringano E, Cramer R, Hayes W, Smith C, Gibson T, MuellerHarvey I (2011) Deciphering the complexity of sainfoin (Onobrychis viciifolia) proanthocyanidins by MALDITOF mass spectrometry with a judicious choice of isotope patterns and matrixes. Anal Chem 83:4147-4153. https:// doi.org/10.1021/ac2003856

Symma N, Sendker J, Petereit F, Hensel A (2020) Multistep analysis of Diol-LC-ESI-HRMS data reveals proanthocyanidin composition of complex plant extracts (PAComics). J Agric Food Chem 68:8040-8049. https://doi.org/ 10.1021/acs.jafc.0c02826

Takahata Y, Ohnishi-Kameyama M, Furuta S, Takahashi M, Suda I (2001) Highly polymerized procyanidins in brown soybean seed coat with a high radical-scavenging activity. J Agric Food Chem 49:5843-5847. https://doi.org/10. 1021/jf010307x

Tanaka T, Takahashi R, Kouno I, Nonaka G-i (1994) Chemical evidence for the de-astringency (insolubilization of tannins) of persimmon fruit. J Chem Soc Perkin Trans 1:3013. https://doi.org/10.1039/P19940003013

Taylor AW, Barofsky E, Kennedy JA, Deinzer ML (2003) Hop (Humulus lupulus L.) proanthocyanidins characterized by mass spectrometry, acid catalysis, and gel permeation chromatography. J Agric Food Chem 51:4101-4110. https://doi.org/10.1021/jf0340409

Toro-Uribe S, Montero L, López-Giraldo L, Ibáñez E, Herrero M (2018) Characterization of secondary metabolites from green cocoa beans using focusing-modulated comprehensive two-dimensional liquid chromatography coupled to tandem mass spectrometry. Anal Chim Acta 1036:204-213. https://doi.org/10.1016/j.aca.2018.06.068
Torres JL, Lozano C (2001) Chromatographic characterization of proanthocyanidins after thiolysis with cysteamine. Chromatographia 54:523-526. https://doi.org/10.1007/ BF02491211

Tuominen A, Karonen M (2018) Variability between organs of proanthocyanidins in Geranium sylvaticum analyzed by off-line 2-dimensional HPLC-MS. Phytochemistry 150:106-117. https://doi.org/10.1016/j.phytochem.2018. 03.004

Vallverdú-Queralt A, Meudec E, Eder M, Lamuela-Raventos RM, Sommerer N, Cheynier V (2017a) Targeted filtering reduces the complexity of UHPLC-Orbitrap-HRMS data to decipher polyphenol polymerization. Food Chem 227:255-263. https://doi.org/10.1016/j.foodchem.2017. 01.106

Vallverdú-Queralt A, Meudec E, Eder M, Lamuela-Raventos RM, Sommerer N, Cheynier V (2017b) The hidden face of wine polyphenol polymerization highlighted by high-resolution mass spectrometry. ChemistryOpen 6:336-339. https://doi.org/10.1002/open.201700044

van Huynh A, Bevington JM (2014) MALDI-TOF MS analysis of proanthocyanidins in two lowland tropical forest species of Cecropia: a first look at their chemical structures. Molecules 19:14484-14495. https://doi.org/10.3390/ molecules190914484

Venter P, Muller M, Vestner J, Stander MA, Tredoux AGJ, Pasch H, de Villiers A (2018) Comprehensive three-dimensional $1 \mathrm{c} \times 1 \mathrm{c} \times$ ion mobility spectrometry separation combined with high-resolution ms for the analysis of complex samples. Anal Chem 90:11643-11650. https:// doi.org/10.1021/acs.analchem.8b03234

Xie D-Y, Dixon RA (2005) Proanthocyanidin biosynthesisstill more questions than answers? Phytochemistry 66:2127-2144. https://doi.org/10.1016/j.phytochem.2005. 01.008

Yanagida A, Murao H, Ohnishi-Kameyama M, Yamakawa Y, Shoji A, Tagashira M, Kanda T, Shindo H, Shibusawa Y (2007) Retention behavior of oligomeric proanthocyanidins in hydrophilic interaction chromatography. J Chromatogr A 1143:153-161. https://doi.org/10.1016/j.chroma. 2007.01.004

Yang Y, Chien M (2000) Characterization of grape procyanidins using high-performance liquid chromatography/mass spectrometry and matrix-assisted laser desorption/ionization time-of-flight mass spectrometry. J Agric Food Chem 48:3990-3996. https://doi.org/10.1021/jf000316q

Zhang LL, Lin YM (2008) HPLC, NMR and MALDI-TOF MS analysis of condensed tannins from Lithocarpus glaber leaves with potent free radical scavenging activity. Molecules 13:2986-2997. https://doi.org/10.3390/ molecules 13122986

Publisher's Note Springer Nature remains neutral with regard to jurisdictional claims in published maps and institutional affiliations. 